\title{
SOB O ARCO-ÍRIS. MIGRAÇÃO, PRECARIEDADE E PODER POPULAR NA ÁFRICA DO SUL PÓS-APARTHEID
}

\author{
Under the Rainbow: Migration, Precarity and People Power \\ in Post-Apartheid South Africa
}

Carl-Ulrik Schierup*

\begin{abstract}
Resumo. O artigo discute a precariedade como um ponto de convergência para a resistência, assim como uma condição social ligada à transição da elite na África do Sul pós-apartheid. Concentrando-se nas forças sistêmicas que impulsionam pobreza, desigualdade e meios de subsistência precários, o artigo aborda a transformação da força de trabalho da África do Sul e seu sistema migratório desde uma gestão centralizada de trabalho não-livre pela burocracia estatal do apartheid para um Estado de precariedade pósapartheid movido pela "flexploitation". O nexo entre o trabalho precário e uma fratura da cidadania é visto como um "dualismo da flexibilidade" que liga práticas de emprego e controle do trabalho a áreas como benefícios sociais, status de cidadania, participação política e meios de subsistência informais. Isso é aplicável tanto aos migrantes como aos nativos, sendo os migrantes particularmente "flexíveis". O autor conecta a questão da precariedade com a política da xenofobia, vista como um estratagema para a manutenção de uma hegemonia política pós-apartheid no enfrentamento das desafiadoras lutas laborais e uma cidadania insurgente dos pobres.
\end{abstract}

Palavras-chave: sociologia; economia política; precariedade; migração; desigualdade social; movimentos sociais; racismo; África do Sul.

Abstract. The paper discusses precarity as a rallying point for resistance as well as a social condition linked to elite transition in post-apartheid South Africa. Focusing on systemic drivers of poverty, inequality and precarious livelihoods, it discusses the transformation of South Africa's labour force management and its migratory system from a centralised management of unfree labour by the apartheid state bureaucracy to a post-apartheid state of precarity driven by 'flexploitation'. The nexus of precarious work and a fracturing citizenship is seen to represent a 'duality of flexibility' linking practices of employment and labour control to areas like welfare benefits, citizenship status, political participation and informal livelihoods. This is applicable to migrants and natives alike, but with migrants being

* Linköping University. Suécia. 
particularly 'flexible'. The author connects the issue of precarity with politics of xenophobia seen as a stratagem for the retaining of a postapartheid political hegemony in confronting looming labour struggles and an insurgent citizenship of the poor.

Keywords: sociology; political economy; precarity; migration; social inequality; social movements; racism; South Africa.

So in a way the thing was new. Yet the stories that were sometimes heard about it were not of something young and vigorous, but the same old stories of money changing hands and throats getting moistened and palms getting greased. Only this time if the old stories arose any anger, there were nowhere for it to go. The sons of the nation were now in charge, after all.

Ayi Kwei Armah, The Beautiful Ones are not yet Born (1968)

\section{Ubuntu destruído ${ }^{12}$}

O "apartheid" foi utilizado como uma densa metáfora nos estudos da economia política da migração, cidadania e trabalho, tanto no "Norte" quanto no "Sul" global ${ }^{3}$. Foi usado como um caso típico de "trabalho não-livre"4, fundado na violência de classe, exclusão dos direitos de cidadania e expulsão

1 Este é um documento de trabalho parcialmente revisado apresentado no seminário REMESO no Institute for Research on Migration, Ethnicity and Society, no dia 11 de novembro de 2015. Foi registrado no repositório DIVA da Universidade Linköping no dia 2 de dezembro de 2015. O artigo é o primeiro rascunho de um manuscrito publicado posteriormente no volume da editora Brill: Politics of Precarity: Migrant conditions, struggles and experiences (2016). Uma versão mais curta do artigo foi publicada na revista Critical Sociology (2016). Artigo traduzido do inglês pela equipe do CSEM.

2 Agradeço o financiamento generoso do Swedish Research Council for Health, Working Life and Welfare (FORTE grant No. 2006-1524) através de uma Bolsa de Pesquisa do Swedish Research Council [No. 2013-6682].

3 Por exemplo, "apartheid americano", que descreve as condições de uma "subclasse racializada" nos Estados Unidos (Massey, Denton, 1993); o "apartheid europeu" do regime de cidadania do século 21 da União Européia (Balibar, 2004, p. 121); o "apartheid econômico" do Canadá "multicultural" (Galabuzi, 2006); o "apartheid social" no Brasil (Hunt, 2007); a Arábia Saudita como "o Estado real de Apartheid do Oriente Médio" (Greenfield, 2014) e a declaração de uma Palestina "independente" como que mascarando a realidade política e social de um "bantustão disfarçado" (Eid, 2015).

4 Contradizendo, assim, a doutrina marxista que vê o "trabalho livre" como o caráter por excelência do trabalho sob o capitalismo, que é a "liberdade" do trabalhador assalariado da propriedade dos meios de produção, mas também sua liberdade básica para vender seu trabalho através da negociação, assinatura ou encerramento de um contrato de emprego (Marx, 1976 [1885]). Mais amplamente, refletindo sobre as novas tendências na migração internacional do trabalho na década de 1980, Miles (1987) e Cohen (1987) argumentaram que o "trabalho não-livre" reflete mais apropriadamente as condições reais de uma ampla gama de trabalhadores sob o capitalismo, no passado e no presente. Trabalhadores esses que são expostos à exclusão social, ao racismo, à segmentação discriminatória do mercado de trabalho e às formas diferenciais de coerção formal e informal, não sendo, assim, capazes de fazer circular livremente o seu trabalho no mercado. 
para as subjugadas terras de origem, e legitimado por mitologias de raça, cultura, etnia ou identidade nacional. No entanto, o movimento antiapartheid - e sua luta por uma sociedade democrática não-racial - foi, simultaneamente, uma das mais importantes lutas emancipatórias anticoloniais do século XX. Nesse duplo sentido, a memória do apartheid permaneceu crucial para os estudos sociais críticos. Da mesma forma, os desafios, as disjunções, as lutas sociais e a ainda indefinida trajetória do desenvolvimento pós-apartheid da África do Sul continuam sendo essenciais para a pesquisa sobre migração, pós-colonialismo e imperialismo em sua aparência neoliberal de "globalização" - alegoricamente denominado de "apartheid global" (Bond, 2004; cf. Richmond, 1994).

No final da década de 1980, a longa luta contra o apartheid na África do Sul, liderada pelo Congresso Nacional Africano (ANC, em inglês), alcançou sua vitória. O ANC, apoiado por uma aliança com o Partido Comunista Sul-Africano (SACP, em inglês) e o Congresso dos Sindicatos Sul-Africanos (COSATU, em inglês), no início dos anos de 1990, entrou em negociações com o antigo inimigo e alicerce político do apartheid, o Partido Nacional, liderado por Africânderes brancos. Isso resultou no fim formal do apartheid, em 1994, a convocação de eleições democráticas livres e a ascensão de um novo governo liderado pelo ANC. A África do Sul nascida desta "Revolução Nacional Democrática" seria transformada em uma "Nação Arco-Íris" inclusiva. Trata-se de uma metáfora cunhada pelo vencedor do Prêmio Nobel, o arcebispo Desmond Tutu, para designar a nova comunidade multicultural de um "Povo Arco-Íris de Deus", em um país anteriormente marcado pela profunda divisão do apartheid entre brancos e negros. Era o sonho de um "excepcionalismo" da África do Sul não-racial, incorporado na filosofia do Ubuntu, que fala da "própria essência do ser humano" (Tutu, 1999, p. 1) em termos de vínculos universais de compaixão, partilha, cuidado e generosidade. Ela abrange o valor da hospitalidade africana ilustrada pela parábola de Nelson Mandela de um "viajante que atravessava o seu país" e que "poderia parar em uma aldeia sem ter que pedir comida ou água" (Mandela, 2012). Parábola essa que valoriza os princípios do perdão e da pacificação que orientaram a célebre Comissão de Verdade e Reconciliação sul-africana, a qual, supostamente, encerraria a era da opressão classista e racial e da violência interna do apartheid.

Em síntese, Ubuntu foi descrito como um tipo sul-africano de discurso humanitário que surge "como uma ponte consensual entre as tradições racistas coloniais reformadas da elite nacionalista branca que está saindo e o nacionalismo africano reformado daqueles que estão chegando" (Neocosmos, 2011, p. 368). No entanto, para as forças políticas de esquerda no movimento contra o apartheid, o estabelecimento da democracia liberal e a igualdade formal 
dos cidadãos representaram uma "revolução inacabada" (Alexander, 2010)5 . A partir dessa perspectiva, o Ubuntu significa mais que um evangelho humanitário. Tal como cristalizado no Congresso da Carta de Liberdade do Povo ${ }^{6}$, de 1955, representa uma visão mais ampla de um movimento ativista de contestação do capitalismo predatório; um contra-movimento que construiria o poder do povo com base em processos irrestritos de organização cooperativa e coletivista (Richards, 2012), inclusive com a promessa de aproveitar os extraordinários recursos naturais da África do Sul para criar meios de subsistência dignos para todos, através da nacionalização das minas e da reparação de séculos de land grabbing por meio da redistribuição da terra "para aqueles que a trabalham".

Idealismos à parte, a Nação Arco-Íris se tornaria, na realidade, um edifício rochoso projetado por "arquitetos da pobreza", conforme o economista político Moeletsi Mbeki (2009). Para as elites de hoje, riquezas e poder emanam, como antes, dos gigantescos recursos subterrâneos de metais e minerais da África do Sul. Contudo, não há um "pote de ouro" no fim do Arco-Íris", mas uma armadilha tóxica de um extrativismo predatório que continua a impulsionar a pobreza e a precariedade do trabalho e da cidadania em uma sociedade ainda profundamente racializada. Substancialmente, não há "nenhum negro no arco-íris" ${ }^{\prime \prime}$, argumenta a defensora de direitos humanos Reshoketswe Mapokgole (2014), em outra exposição crítica na qual descreve uma "xenofobia" multifacetada como "Afrofobia" ou "Negrofobia", que incita negros "nativos" pobres contra negros "estrangeiros" pobres, em uma sociedade onde a desigualdade continua a ser profunda como os oceanos e onde um regime de hiperexploração migratória continua a ser uma das questões mais controversas.

No pano de fundo dessas e de outras opiniões no debate sobre a crise atual que abrange economia, política e sociedade, inserimos este ensaio em um rico leque de pesquisas críticas sobre a África do Sul. Sem pretensão de revisitar os polêmicos debates, frequentemente conflitantes, sobre a transformação pós-apartheid, o objetivo é mesclar perspectivas sobre as políticas populistas e o trabalho migrante em uma economia política transformada com uma visão dialética da precariedade do trabalho e da cidadania.

\footnotetext{
5 A idéia da "Revolução Nacional Democrática" foi formulada pela primeira vez pelo SACP em 1928 e mais tarde adotada como uma carta política para a ampla luta contra o apartheid liderada pelo ANC. O SACP, originalmente, partiu do entendimento de Lênin sobre a Revolução Francesa e, mais tarde, as "revoluções burguesas", incluindo a primeira revolução russa de 1905 como uma revolução ainda "inacabada" (socialista) (Sewell, 2004; Slovo, 1988).

6 Veja ANC (1955).

7 Esta metáfora também foi usada por Alexander (2013, p. 181), argumentando que "teremos que demonstrar ao povo da África do Sul e do mundo que o Arco-Íris nada mais é do que "as cores unidas do capitalismo" e que o pote de ouro não está no fim do Arco-Íris, mas é uma construção ideológica que beneficia os proprietários das minas de ouro da África do Sul e seus investidores multinacionais associados

8 Ecoando o trabalho de Paul Gilroy (1987) "There Ain't No Black in the Union Black".
} 
O texto começa com uma revisão condensada da transição pós-apartheid, enfocando as forças sistêmicas que impulsionam a pobreza, a desigualdade e os meios de subsistência precários. Discutimos a transformação no gerenciamento da força de trabalho sul-africana e seu sistema migratório desde um regime centralizado no trabalho não-livre pela burocracia estatal do apartheid para um Estado de precariedade pós-apartheid movido pela flexploitation (Bourdieu, 1999a, p. 84). Ressaltamos (com Goldring, Landholt, 2011) o complexo entrelaçamento entre o trabalho precário e uma fratura da cidadania; uma fusão sintética de duas tendências na globalização contemporânea. Isso representa um "dualismo da flexibilidade" (Lazaridis, Psimmenos, 2000), conectando práticas de emprego e de controle do trabalho a áreas como benefícios sociais, status de cidadania, participação política e meios de subsistência informais, aplicáveis tanto a migrantes como a nativos, sendo os migrantes particularmente "flexíveis". Seguimos olhando para a política da xenofobia como um estratagema para a manutenção da hegemonia em um momento marcado por fortes lutas trabalhistas e uma cidadania insurgente dos pobres, para além do alcance da governança neoliberal. Nosso argumento gira em torno da "precariedade" enquanto "uma condição e um possível ponto de convergência para a resistência" (Waite, 2008, p. 412).

\section{Trabalho não-livre como legado colonial}

O apartheid, instalado como ideologia dominante na União da África do Sul com a ascensão ao poder do Partido Nacional, dominado pelos Africânderes, em 1948, implicou uma hegemonia branca reestruturada, assentada em uma aliança entre capitalistas de língua inglesa e uma elite política africânder. Além disso, integrou uma classe trabalhadora branca, que se beneficiou da cidadania, do bem-estar social e do acesso privilegiado a ocupações qualificadas, mas expôs, ao mesmo tempo, a maioria da população negra da República a um aprofundamento da privação de direitos, da segregação e do trabalho não-livre. Tal situação representou, como tal, uma nova fase excepcionalmente austera na estratégia de acumulação do capitalismo na África do Sul, marcada pela desapropriação de negros africanos de suas terras e pela produção e reprodução de um sistema de migração projetado para a hiperexploração do trabalho não-livre barato.

Diferentes práticas africânderes para "transformar os povos indígenas em trabalhadores assalariados não-livres" (Terreblanche, 2003, p. 9), que remetem ao assentamento branco do século XVII, foram remodeladas no contexto de um capitalismo racial impulsionado pelo Estado e institucionalmente incorporado sob o domínio colonial britânico do século XIX (Keegan, 1982). A mineração de ouro, que começou em meados do século XIX, gerou uma demanda crescente por mão de obra não-livre barata. Os esforços para 
criar um suprimento estável de mão de obra africana de baixo custo para as minas sob o domínio colonial, progressivamente, produziram um sistema de trabalho migrante pendular rural-urbano, centralmente monitorado, que cobria grandes áreas da África meridional; um antecedente e um modelo para a gestão do trabalho em tempos posteriores na economia sul-africana (Jeeves, 1985; First, 1982).

Após o fim da Guerra da África do Sul e o estabelecimento da União da África do Sul como domínio britânico, em 1910, uma elite política africânder, com habilidades comprovadas na administração do Estado e na obtenção efetiva de mão de obra não-livre negra e barata, tornou-se uma aliada estratégica dos anglo-capitalistas brancos que controlavam o setor da mineração. Na época, tal situação foi propiciada por uma potencial aliança com uma elite profissional e empresarial negra, enraizada no colonialismo britânico do século XIX (Mbeki, 2009). As "Reservas Nativas" - instituídas pela Lei de Terras de 1913 e baseadas em uma aliança entre as empresas de mineração controladas pela Inglaterra e os latifundiários africânderes - representaram um amplo passo jurídico-institucional na alienação de negros africanos de suas terras e no fortalecimento do regime de trabalho migrante não-livre.

O apartheid, formalmente instituído em 1948, remodelou e agravou ainda mais esse processo histórico de alienação. Transformou os antigos "nativos" em "estrangeiros", mediante a lógica do chamado "desenvolvimento separado", que está implícita nas "pátrias encolhidas" (homelands) denominadas bantustões (bantustans), a saber, falsos "estados-nação" sob a autoridade espúria de "chefes nativos" . Isso impediu os africanos negros de residir na República da África do Sul "branca" - através de um regime trabalhista centralizado e monitorado pelo Estado, mediante uma forte burocracia estatal e um rigoroso regime de segurança -, o que enjaulou milhões de "nativos estrangeiros" alienados (Neocosmos, 2015) em uma condição permanente de migração rural-urbana e trabalho não-livre (Wolpe, 1972). O controle dos fazendeiros brancos sobre a vasta maioria das terras agrícolas (progressivamente tomadas pelos colonizadores durante séculos de domínio colonial) e a taxação discriminatória dos pequenos proprietários negros privaram a população rural africana da segurança da propriedade da terra. Isso foi associado à contratação de mão de obra temporária administrada por agências centralizadas, à construção de recintos arregimentados de trabalhadores migrantes em áreas de mineração e cidades periurbanas e a leis de mobilidade restritiva projetadas para conter o assentamento urbano negro (Frankel, 1979). A política de segregação urbana incluía a demolição de bairros racialmente mistos em favor da construção de municípios periurbanos negros. Através de uma bantustanização

\footnotetext{
9 Uma versão renovada do domínio indireto colonial.
} 
(Bantustanisation) administrativa de municípios, muitos moradores urbanos perderam o direito de residir na África do Sul e, com efeito, ficaram sujeitos ao regime de contrato de trabalho. A política de "remoção forçada" envolveu o reassentamento de negros sul-africanos de municípios e áreas rurais brancas para os bantustões (Henrard, 1995-96).

O sistema de trabalho migrante do apartheid, na África do Sul, foi acompanhado por um regime regional sul-africano mais vasto de contratação de mão de obra migrante para as minas, a agricultura comercial e as indústrias do país. Assim como a migração dentro do território da África do Sul, isso iniciou em meados do século XIX, quando as indústrias coloniais de mineração de diamantes e ouro foram fundadas, e prosseguiu ao longo do século XX. No período colonial, as comunidades provedoras de migrantes em toda a região da África meridional eram controladas através do "governo indireto", em aliança com autoridades "nativas" (por exemplo, Mamdani, 1996); durante o apartheid continuou mediante a colaboração de Pretória com "chefes tradicionais" nos bantustões e com sua influência política em toda a região. Os trabalhadores migrantes foram recrutados de todos os territórios e Estados fronteiriços ${ }^{10}$, com a maioria dos quais a República estipulou acordos bilaterais de recrutamento (Wentzel, Tlabela, 2006). Nas minas da África do Sul, $40 \%$ da força de trabalho eram de não sul-africanos, durante a maior parte do século XX, chegando a 60\% na época da libertação (Cruch, 2003, p. 3). A migração para as minas estava formalmente e em grande medida regulamentada durante o apartheid, enquanto o trabalho indocumentado era mais comum na agricultura. Predominava uma migração circular, em harmonia com o controle dos assentamentos de negros em áreas urbanas. A migração "interna" bantustanizada envolvia incontáveis trabalhadores não-assalariados, principalmente mulheres, nas comunidades de origem; uma pré-condição para a reprodução de uma força de trabalho migrante, principalmente masculina, mal paga e hiper-explorada (Wolpe, 1972). Contudo, ao passo em que foi abandonado o controle do afluxo de migrantes urbanos nos bantustões, em 1986, os trabalhadores transfronteiriços nunca receberam a residência.

\section{Do fordismo racial à precariedade neoliberal}

O apartheid, e seu sistema integral de mão de obra não-livre imigrante, negra e hiperexplorada, foi projetado para atender principalmente às necessidades de trabalho da indústria de mineração e da agricultura capitalista. Mesmo assim, entrou em conflito com reivindicações capitalistas rivais, uma vez que a África do Sul estava se tornando o Estado em desenvolvimento mais industrializado da África por meio de uma política de substituição de

\footnotetext{
${ }^{10}$ Atualmente, Moçambique, Lesoto, Zimbábue, Malawi e Suazilândia, entre outros.
} 
importações (por exemplo, Legassick, Wolpe, 1976). Era uma versão particular de "fordismo periférico" (Lipietz, 1982); um "fordismo racial" (Gelb, 1987), em que o dinamismo industrial e a diferenciação econômica foram freados pelo profundo dualismo racial do apartheid e por uma economia política baseada em um esquema de acumulação (pós-) colonial de dependência da trajetória (path dependent). Essa disjunção foi identificada como um fator importante do declínio econômico de longo prazo nos anos de 1980, uma situação estrutural exacerbada que permaneceu na África do Sul democrática do novo milênio, apesar das mudanças radicais da estrutura política e das relações de raça e classe (Mbeki, 2009).

A década que precedeu o desmoronamento final do apartheid, no início dos anos de 1990, foi marcada por uma recessão econômica, sanções internacionais e crescentes rupturas na hegemonia branca. A exclusão de africanos negros de profissões qualificadas tornou-se cada vez mais prejudicial para setores influentes do capital. Ao mesmo tempo, um poderoso movimento social antiapartheid - em particular, a força crescente de um "sindicalismo comunitário" que abria caminhos em locais de trabalho, municípios negros, cidades e áreas rurais, com os trabalhadores migrantes à frente (Bramble, 2003) - transformou a estratégia do apartheid de procurar mão de obra barata em um beco sem saída.

A Convenção para uma África do Sul Democrática (CODESA, em inglês), negociada entre o ANC e o Partido Nacional no início dos anos de 1990, pôs fim ao apartheid e se manifestou mediante as primeiras eleições universais multipartidárias, em 1994. Estabeleceu uma democracia política não-racial, uma cidadania universal e evitou uma prolongada guerra civil; pagou o preço, no entanto, de um compromisso com o capital corporativo nacional e internacional que, reforçado pelas pressões das instituições monetárias internacionais, acabou renunciando aos valores da igualdade social e políticas de redistribuição que eram cruciais para os sindicatos, o SACP e as facções de esquerda do ANC. Abandonaram-se, além disso, as demandas por nacionalização das minas e reforma agrária, que beneficiariam a população rural pobre. Isso acelerou, de fato, um desenvolvimento que já tinha sido iniciado durante o apartheid da década de 1980, num período assolado por crises, com a transformação de um regime regulado pelo Estado, característico do Estado desenvolvimentista da África pós-colonial, para um regime neoliberal (Buhlungu, 2010). Em 1996, isso foi estabelecido em um programa de ajuste estrutural neoliberal, o Programa Crescimento, Emprego e Redistribuição (GEAR, em inglês), que implicava o desmantelamento das regulamentações da moeda nacional, a adoção de acordos de livre comércio, a redução de impostos, a reestruturação das corporações em detrimento dos direitos trabalhistas e da organização dos trabalhadores, a redução do estado de bem-estar social e a privatização dos 
serviços públicos. A aliança original tripartite do Programa neo-keynesiano de Reconstrução e Desenvolvimento (RDP, em inglês), liderada pela COSATU, foi posta de lado juntamente com a visão de um "pacto social" socialdemocrata pós-apartheid mercado pela prioridade no crescimento do emprego e por uma política redistributiva inclusiva para combater a pobreza e a desigualdade social (Maharajh, 2011; Barchiesi, 2011).

Uma vertente da pesquisa crítica sul-africana focaliza a "transição da elite" e a mudança de alianças de raça e classe que impulsionaram este desenvolvimento: de "governantes políticos africânderes brancos a negros em Pretória, com os capitalistas brancos de língua inglesa de Joanesburgo conservando o controle global da economia e, ainda, autorizados a desinvestir suas riquezas da era do apartheid" (Bond, 2000, p. 575). A transição - argumenta Mbeki (2009, p. 39-100) - reflete o persistente poder e a influência pós-apartheid do Complexo de Energia Mineral (MEC, em inglês) sul-africano, liderado - segundo Sampie Terreblanche (2003, p. 95ff) em seu monumental trabalho sobre a história da desigualdade na África do Sul pela poderosa corporação anglo-americana Anglo-American Corporation em uma "quarta fase" da busca por uma estratégia vantajosa de acumulação, no momento em que o apartheid centralizado pela burocracia estatal e seu vasto aparato de segurança - sob impacto da sindicalização e a luta contra o apartheid - tinha cumprido seu papel na obtenção de mão de obra barata para a indústria da mineração. Os "oligarcas" do MEC intensificaram, nesta altura, a busca por uma nova aliança com a moderna classe média negra sul-africana liberal e urbana, cujas raízes remontam ao colonialismo britânico e que, historicamente, havia sido uma força propulsora dentro do ANC. O ponto central desta aliança era alcançar o chamado empoderamento econômico negro ("Black Economic Empowerment") (BEE). Isso significou uma transferência de ações corporativas para um número limitado de indivíduos negros, designados como indivíduos anteriormente em desvantagem (Previously Disadvantaged Individuals) (PDIs), incluindo líderes sindicais proeminentes, com o objetivo manifesto de apoiar a construção de uma burguesia negra próspera. Acreditava-se que seus efeitos iriam supostamente "se derramar" e aliviar a pobreza da maioria negra. Um passo inicial nesse sentido foi a criação da Comissão do Empoderamento Econômico Negro (Black Economic Empowerment Commission) (BEEC), em 1998, presidida por Cyril Ramaphosa, que, nos anos de 1980, foi um proeminente líder sindical que recebeu crédito pela construção de um dos sindicatos mais importantes da África do Sul, o Sindicato Nacional de Mineiros. Hoje é presidente do ACN e do país, e um dos indivíduos mais ricos e poderosos da África do Sul ${ }^{11}$.

\footnotetext{
11 A legislação formal do BEE foi aprovada em 2003 e, em seguida, alterada consecutivamente.
} 
Através de sua aliança com uma emergente elite política e econômica negra, a oligarquia do MEC poderia manter o controle dos enormes recursos naturais da África do Sul, enquanto, ao mesmo tempo, com a ajuda do pacto neoliberal, salvaguardaria seu capital contra possíveis perturbações políticas, transferindo as sedes corporativas e os lucros para o exterior (Bond, 2013, p. 575). O acordo proporcionou uma abertura radical para a importação de bens de consumo manufaturados, o que reduziu o custo da mão de obra para o MEC, mas significou também uma destrutiva competição internacional para o setor manufatureiro doméstico que não era do MEC, a redução de empregos permanentes e a criação de empregos precários principalmente nos setores do varejo e serviços (Mbeki, 2009; Newman, Takala-Greenish, 2014; Barchiesi, 2011). Isso resultou na formação de um enorme precariado sul-africano pós-apartheid, preso entre uma rede tóxica de agências que geram trabalho temporário, contingente e inseguro e a mercantilização das políticas "des-racializadas" para combater a pobreza e a desigualdade.

A partir dessa perspectiva, o crescimento de políticas de transferência de renda e de prestação de serviços e aquisição de moradia para sul-africanos pobres, durante os anos $2000^{12}$, podem ter servido para assegurar meios de subsistência, impulsionar a hegemonia do ANC e garantir sua vitória em eleições gerais consecutivas. Isso manteve os pobres à espera de um imaginado sistema de distribuição de riqueza ${ }^{13}$ mais prolífico que, no entanto, dificilmente se materializará sob as condições da economia política vigente. "[N]egros que haviam sido reduzidas a um proletariado empobrecido e vulnerável pelo cruel sistema do apartheid estavam agora expostos à implacável tirania das forças do 'livre-mercado'" (Terreblanche, 2003, p. 77). Em última análise, sustentou Terreblanche em 2003, a Nação Arco-Íris continuou a reproduzir uma condição desalentadora de pobreza multidimensional e exclusão sistêmica entre os negros pobres, herdada da fase tardia da crise do apartheid. Similarmente, dez anos depois, a OXFAM concluiu em um relatório (2013), que apenas marginalmente se enfrentou o "tríplice desafio" da "pobreza, desigualdade e desemprego".

De acordo com as estatísticas do Banco Mundial ${ }^{14}$ em 2011, mais da metade de todos os sul-africanos viviam abaixo da linha de pobreza nacional - cerca de quatro dólares por dia -, mais que o dobro do que no México, no Brasil ou no Peru. Este nível excepcionalmente alto de pobreza para um país de renda média reflete a aparente incapacidade da África do Sul de reduzir a desigualdade. Medida por um coeficiente de Gini próximo a 0,70, a África

\footnotetext{
${ }_{12}$ Para detalhes, veja a República da África do Sul (2013).

${ }^{13}$ N.T: Trickle down, no original, se refere a um Sistema econômico em que os mais pobres se beneficiam gradualmente como resultado da crescente riqueza dos mais ricos.

${ }^{14}$ Fonte: World Bank Poverty and Inequality Statistics, Abril de 2015.
} 
do Sul tem uma das maiores taxas de desigualdade do mundo, superando os Estados Unidos (Gini 41), Brasil (53) ou Rússia (40, em 2009), três das sociedades mais desiguais do globo. A desigualdade na renda não se limita a salários e riqueza, mas abrange também os meios de ter acesso e o uso de serviços, bens públicos e recursos naturais (OXFAM, 2013). Um fator que impulsiona a pobreza e a desigualdade é o desemprego - $25 \%$ de acordo com as estatísticas oficiais, mas próximo de $40 \%$ se contarmos os que desistiram de se candidatar ao emprego formal. O desemprego é particularmente alto entre negros pobres, jovens negros e nas antigas áreas dos bantustões (Leibbrandt et alii, 2009, p. 12; OECD, 2013). Uma profunda desigualdade racial e de classe é reproduzida por meio de um serviço de saúde público-privado de dois níveis e um sistema escolar que não favorece a juventude negra pobre em termos de qualidade educativa, taxas de aprovação e perspectivas de emprego.

A desigualdade média de renda inter-racial diminuiu durante o período pós-apartheid, mas permanece expressiva. Em comparação, a desigualdade intra-racial entre negros sul-africanos aumentou. A representação de negros entre os estratos profissionais e gerenciais cresceu de forma substancial. Aumentou o número daqueles que conseguiram entrar nas elites profissionais e empresariais do país através de, entre outros fatores, ações afirmativas e do BEE, mas às custas da exploração continuada de um enorme exército de reserva de mão de obra barata e precária, particularmente entre mulheres negras, jovens, migrantes internos e transfronteiriços (Gentle, 2011). A pobreza e o desemprego continuam concentrados nas antigas áreas dos bantustões, mas com uma tendência de crescimento cada vez maior nos assentamentos informais periurbanos, a saber, "povoados" negros com condições de moradia similares às "shanty towns" ou "favelas" dos países menos favorecidos do mundo, e com um alto fluxo de migrantes africanos internos e transfronteiriços. São pessoas pobres que foram despejadas, uma vez que suas casas estavam na linha de frente da privatização de habitação, pela gentrificação urbana ou por prestigiosos projetos governamentais; esses pobres se concentraram, sempre e de novo, nos "blikkies" (barracos de ferro ondulado) das chamadas "áreas de realocação temporária" (Ranslem, 2015).

Não obstante essas tendências, uma análise mais adequada daquela oferecida pelos críticos da suposta trajetória neoliberal da África do Sul, sustenta Habib (2013) em South Africa's Suspended Revolution, deveria ser construída em uma compreensão ponderada das mudanças de poder decorrentes da progressiva democratização. A marginalização dos parceiros de esquerda do ANC (COSATU e SACP) dentro da aliança tripartite, nos anos 90, deve ser vista no contexto do surto político neoliberal global da época, um poder esmagador do capital corporativo no momento da transformação democrática inicial da República, juntamente com o contínuo controle do Partido Nacional 
sobre o exército e a polícia. Devido à democratização, os equilíbrios de poder mudaram durante a década de 2000 com o fortalecimento do COSATU e do SACP e o empoderamento de uma sociedade civil pós-apartheid diversificada e crítica. Significou uma reorientação progressiva na política social e no desenvolvimento de infraestruturas, em particular após a eleição de Jacob Zuma - supostamente de esquerda - como líder do ACN, em 2007, e como Presidente da República em 2009 (apoiado pelo COSATU, o SACP e o ANC Youth Alliance). Zuma substituiu o neoliberalismo por um regime neokeynesiano socialdemocrata de fato, com "esperanças e perspectivas" para a formação de um novo pacto social inclusivo.

Essa narrativa alternativa parece, no entanto, ter olvidado o que, no contexto europeu, foi discutido em termos de virada neoliberal da Terceira Via da socialdemocracia, racionalizando uma transformação dos Estados de bem-estar do Norte através da mercantilização da política social, da saúde, dos serviços públicos e da infraestrutura, com consequências amplamente polarizantes em termos de classe e "raça" (Schierup, Alund, Kings, 2014). Uma política semelhante de "comercialização disfarçada" (McDonald, Ruiters, 2012, p. 170) foi aplicada pelo FMI e pelo Banco Mundial para transformar o Estado desenvolvimentista no Sul global. Uma trajetória análoga na África do Sul foi analisada pelos críticos em termos de "Zuma's Own Goal" (Maharaj, Desai, Bond, 2011), que está perdendo a "guerra" da Nação Arco-Íris "contra a pobreza", através da elaboração de uma agenda de política mercantil incorporada em uma política fiscal austera, do tipo "talk left, speak right" (Bond, 2014).

Trata-se de uma política de fornecimento de "Serviços Básicos Gratuitos", que garantem um mínimo de água e eletricidade para as famílias pobres. No entanto, é uma política ameaçada por seu vínculo com uma doutrina neoliberal de "recuperação de custos", que autoriza os provedores de serviços a cobrar preços exorbitantes por tudo o que ultrapassa o mínimo necessário, a subcontratar prestação de serviços públicos junto a corporações privadas ou ONGs e a estabelecer sistemas austeros de pré-pagamento para necessidades básicas. Isso ocorre em conjunto ao subsídio de empresas privadas ("Corporate Welfare"), o que significa fornecer eletricidade com desconto aos usuários da indústria, especialmente o MEC, enquanto "os cidadãos não podem ter um fornecimento confiável a qualquer preço" (Bond, 2006; também Bond, 2012b). Isso equivale à promoção de uma política pública de "capitalismo elétrico", com consequências negativas para a saúde, a equidade de gênero, a sustentabilidade ambiental e a justiça socioeconômica (McDonald, 2012). O "microcrédito" é outro instrumento de suposto combate à pobreza. No entanto, se desenvolve distorcendo as regras e os mecanismos de administração dos grandes bancos sul-africanos e, de acordo com vários estudos detalhados, 
funciona como outro meio de "acumulação através da expropriação"15, empurrando as estratégias de sobrevivência à beira da "escravidão" por dívida e incentivando as divisões de raça, classe e gênero (Bateman, 2014; Hietalahti, 2013). Refere-se, finalmente, à imersão das políticas de transferências sociais financiadas pelo Estado em um casamento disfuncional entre regulações paternalistas do regime econômico de dependência da trajetória (path dependent), remanescente da era do apartheid, e uma disciplinar avaliação de recursos marcada pelo rigor fiscal. Embora desracializadas e amplamente espraiadas, tais políticas são vistas como substancialmente "simbólicas", sem a capacidade de tirar o peso do mundo ${ }^{16}$ das costas dos pobres da África do Sul (Bond, 2014). É um impasse, argumenta Barchiesi (2011), que precisa ser discutido focando o nexo entre cidadania disciplinar e trabalho precário.

\section{Caprichos da flexploitation}

Um elemento crítico na transformação pós-apartheid da África do Sul foi a desracialização da legislação trabalhista durante a segunda metade da década de 1990, através da qual a legislação do apartheid (introduzida para proteger operários brancos, sindicalizados qualificados e semi-qualificados) foi reformada e ampliada para cobrir todos os trabalhadores sul-africanos sindicalizados, qualificados e semi-qualificados. Desta maneira, uma legislação que anteriormente protegia os privilégios de uma elite de trabalhadores brancos deveria, a partir desse momento, garantir os privilégios para uma elite de trabalhadores pós-apartheid, de "qualquer raça ou pele" (Seekings, 2007, p. 18). Entretanto, na mesma instância, argumenta Seekings, deslocou os "vestígios da era do apartheid, da divisão entre insiders e outsiders, de dentro do local de trabalho [para] fora dele, de modo que os (formalmente) empregados se tornassem todos insiders enquanto os desempregados, trabalhadores casuais e empregados informais permanecessem outsiders". Aqui Seekings, seguindo seu trabalho com Nattrass (2005), focaliza um dos aspectos que promovem a pobreza e a desigualdade na África do Sul pós-apartheid. No entanto, o argumento sucumbe a uma fraqueza semelhante à de Standing (2011), que vê o "precariado" como uma "classe" particular para além dos interesses internos do que sobra da classe trabalhadora protegida e privilegiada do fordismo e dos sindicatos que os representam; enquanto, segundo Seymour (2012), "a precariedade exerce efeitos sobre a cadeia de estratos de classe, em toda a classe trabalhadora e em setores da classe média". Considerar uma oposição duradoura entre "insiders" privilegiados e "outsiders" sem qualificações e emprego formal, se torna insuficiente face a um discurso político e intelectual pós-apartheid sobre "flexibilidade" que

\footnotetext{
${ }^{15}$ Referindo-se a Harvey (2005).

${ }^{16}$ Minha alusão a Bourdieu (1999b).
} 
entrou na realidade social como uma "força material" (Bezuidenhout, Kenny 2000; Bezuidenhout, Godfrey, Theron, 2004).

Essa "força" representa, como em outros lugares (Schierup et alii, 2015), um imenso desafio para os sindicatos. Manifesta-se na legislação que promove a mercantilização do trabalho e não menos na instalação de um estado de flexibilidade "quo ante bellum" por meio da informalidade, que desconsidera ou encobre regulamentações formais. A triangulação do emprego; a "externalização do trabalho" através da terceirização (outsourcing), a subcontratação; e o deslocamento da responsabilidade sobre recrutamento, emprego, salário e condições de trabalho desde grandes corporações lucrativas para as práticas de uma multiplicidade de intermediários laborais privados foram identificados como motores da informalização do trabalho e do crescimento de novas formas de trabalho não-livre (Benjamin, 2013b, 2013a), perpetuando o legado de exploração sistêmica do colonialismo e do apartheid (Terreblanche, 2003). Assim, uma multiplicidade de práticas corporativas obscuras de uma "informalização desde cima" (Theron, 2010b) substituiu a força extraeconômica de cima para baixo do apartheid como guia para uma massa precária, socialmente insegura e destituída de poder, e circunscrita ao trabalho não-livre (Benjamin, 2013a). Esta prescrição é estabelecida pela repressão da ação organizada, estando subordinada à desregulamentação, desindicalização e dissolução étnico-racial de solidariedades mais amplas.

A mão de obra precária é composta majoritariamente por negros, uma parte considerável de migrantes e um número crescente de mulheres. Os espaços que ocupam se tornam, por sua vez, locais de reprodução da "informalização desde baixo", onde os pobres empregam criativas estratégias de subsistência que estão além do alcance das estruturas regulatórias formais ${ }^{17}$. Uma crescente área de indefinição surgiu "onde as fronteiras da produção formal e informal se tornam nebulosas e indistinguíveis ... e onde o emprego dificilmente leva à inclusão social e à cidadania" (Barchiesi, 2010, p. 68). A maioria dos empregados foi registrada na precária categoria de "trabalhadores pobres" (Altman, 2006 p. 11ff). Na vasta zona da informalidade e no vórtice do trabalho temporário, os migrantes têm uma "vantagem comparativa" para muitos empregadores, pois formam uma força de trabalho particularmente barata e flexível. Isso diz respeito aos migrantes transfronteiriços, que são privados do poder de negociação pela condição de despossuídos (Fine, 2014; Gordon, 2010), sobretudo os indocumentados, mas também aos migrantes internos por sua "desvantagem comparativa", sendo encurralados no trabalho não-livre por forças de desenvolvimento regional desigual, pobreza, dívida e seu abandono do trabalho formal (Xulu, 2010).

17 Theron (2010b; cf. Slavnic, 2010). Veja também Schierup (2015). 
Os migrantes dos bantustões estavam na linha de frente da luta contra o apartheid. Ainda assim, permanecem entre os mais desfavorecidos da África do Sul e são frequentemente negligenciados pelos sindicatos (Xulu, 2010; Fine, 2014). Condições abjetas nas antigas áreas dos bantustões os conduzem a municípios pobres, onde compartilham espaços com uma diversidade de pessoas mais desfavorecida da África do Sul, incluindo uma crescente população de trabalhadores migrantes irregulares transfronteiriços, refugiados e solicitantes de refúgio cujas vidas na informalidade são condicionadas por um regime de asilo aparentemente liberal, mas presumivelmente não confiável, que floresce com a corrupção (Northcote, 2015; Amit, 2015). Os migrantes transfronteiriços viajam de regiões vizinhas, onde o regime do apartheid costumava recrutar trabalhadores. No entanto, muitos chegam também como trabalhadores migrantes indocumentados e como refugiados de partes mais distantes da África, como o Congo e a Somália (Tati, 2008).

Sua situação e oportunidades concretas dependem das regiões geográficas das quais eles migram, das dinâmicas específicas a que respondem, das reivindicações em relação ao Estado sul-africano e de suas respectivas habilidades, qualificações e redes (Kok et alii, 2006). Entretanto, em termos gerais, o centro de gravidade da migração transfronteiriça africana passou de um predomínio de contratos de trabalho formalmente regulamentados sob o regime do apartheid para o emprego de trabalhadores indocumentados nos anos 2000 (Tati, 2008; Gordon, 2010; Fine, 2014). A adoção de programas de ajuste estrutural monitorados internacionalmente em toda a África subsaariana, frequentemente combinados com conflitos internos, produziu uma alta confiança nas estratégias de sobrevivência informais, baseadas na migração transfronteiriça e no pequeno comércio, sendo a África do Sul o principal destino. A resposta prevalente da África do Sul tem sido conter a imigração através de uma reafirmação da soberania do Estado mediante políticas migratórias excludentes e securitárias (Evans, 2010, p. 105; Trimikliniotis, Gordon, Zondo, 2008); uma condição reforçada, em 2014, por novas restrições legais à migração transfronteiriça e à aquisição da cidadania (Dube, 2014).

Isso reflete os esforços do ANC para criar, após a libertação, uma nova identidade nacional e uma política de afirmação de direitos de cidadania para os "de dentro" através do exclusivismo em relação aos vizinhos, o que, consequentemente, incita à xenofobia (Fine, 2014; Johnson, 2007). Durante o período pós-apartheid, os "imigrantes ilegais" foram difamados por políticos e pela mídia, sendo também diariamente hostilizados pelos moradores negros "nativos" dos vilarejos. Essa situação foi supostamente exacerbada pelo empoderamento dos oficiais de polícia e pela educação dos cidadãos em "questões migratórias", que inclui o encorajamento em "erradicar" e denunciar 
"imigrantes ilegais" às autoridades estatais (Neocosmos, 2006, p. 96-97). A "Fortaleza África do Sul" (Crush, 1999; Trimikliniotis, Gordon, Zondo, 2008) é assim similar à "Fortaleza Europa" e às "economias emergentes" da África Subsaariana (como Nigéria, Gana e Botswana), que "lucram com a migração irregular enquanto a denunciam"18. Ao contrário de épocas anteriores, quando os migrantes transfronteiriços estavam concentrados na mineração e na agricultura, eles agora se tornaram uma força de trabalho barata e flexível, preferida em uma gama de setores econômicos de baixos salários, incluindo serviços municipais, construção, varejo e saúde (Fine, 2014). Rondas policiais em municípios periurbanos informais e deportações contínuas acontecem paralelamente às entradas a partir de práticas clandestinas de transportadores privados, intermediários trabalhistas e o suposto envolvimento de policiais e outras agências públicas (Kihato, Landau, 2006; Tshabalala, 2015) em corrupção (Amit, 2015). Assim, a regulamentação mais formal e centralizada da migração africana transfronteiriça sob o apartheid foi substituída por um regime predominantemente informal (Segatti, 2011, p. 56), de acordo com uma lógica em que "períodos de 'tolerância' e 'repressão' são convenientemente alternados com períodos de necessidades de trabalho e excesso de mão de obra" (cf. Gordon, 2010).

A migração indocumentada não é um fenômeno inteiramente novo e está longe de ser a única rota para os trabalhadores migrantes africanos na África do Sul contemporânea (por exemplo, Fine, 2014; Vigneswaran, 2007). Ao mesmo tempo, os migrantes não precisam ser "indocumentados" para serem incorporados em novos tipos de trabalho precário informal. Eles podem ser formalmente recrutados através de contratos temporários, podem ser refugiados ou solicitantes de refúgio e, ainda assim, encurralados em redes clandestinas de relações de trabalho informais. Uma série de estudos analisou o impacto diferencial da informalização, das relações trabalhistas espúrias e da manipulação do status de migrante, raça e gênero, entre outros, na agricultura capitalista (Theron, 2010a), nos serviços municipais (Barchiesi, 2011; Miraftab, 2004), no setor da hospedagem (MiWORC, 2014), na manufatura (Barchiesi, 2010) e na indústria da construção civil (Cottle, Rombaldi, 2014).

Ainda assim, é a precarização do trabalho e dos meios de subsistência, fomentada pela estratégia de acumulação pós-apartheid do MEC, que levaria o "contrato social" do ANC com os trabalhadores pobres da África do Sul a um ponto de ruptura (Cohen, 2013). Em 16 de agosto de 2012, esta questão foi colocada sob os holofotes, em nível nacional e internacional, devido ao massacre realizado pelo Serviço de Polícia da África do Sul contra

${ }_{18}$ Tobias (2012, p. 6), citando Guilfoyle (2010, p. 1). 
trabalhadores mineiros que estavam em greve contra as estratégias de gestão da Companhia ${ }^{19}$ de mineração Lonmin, na fronteira com o município de Marikana no cinturão de platina de Rustenburg. Isso foi o clímax macabro de um prolongado conflito trabalhista, envolvendo, de um lado, a administração da empresa, os quadros dirigentes do ANC e o Sindicato Nacional de Mineiros (um dos afiliados mais importantes do COSATU), e, do outro lado, a separatista Associação de Mineiros e Sindicatos da Construção (AMCU, em inglês), que mobilizava os grevistas, incluindo numerosos trabalhadores migrantes.

Esse evento fatal de violência policial afetou internacionalmente a gloriosa reputação do excepcionalismo da África do Sul, levando ao auge a crise iminente do ANC e do movimento trabalhista. No entanto, como comenta amargamente Frankel (2013, p. 163) em um aprofundado estudo sobre a indústria da mineração sul-africana, isso foi apenas um "pequeno massacre" em meio a um oceano de pequenas e silenciadas destruições cotidianas de trabalho, vidas humanas, terras e dinheiro relacionadas ao MEC. Para além dos impecáveis relatórios corporativos que retratam a gestão sustentável da força de trabalho e o desenvolvimento responsável da comunidade, essa "vasta escala de coisas" (Frankel, 2013, p. 163), subjacente ao imbróglio de Marikana, expõe uma extensa e ilícita redução dos padrões laborais (Forrest, 2013) que está na origem de frequentes acidentes de trabalho, lesões, doenças e mortes precoces, com a cumplicidade tanto dos sindicatos, quanto do governo (Frankel, 2013, p. 24ff). Tal situação está relacionada às estratégias metódicas de "informalização desde cima", a uma inepta gestão da migração (Frankel, 2013, p. 82ff) e ao envolvimento "deliberado e programado de uma indústria microfinanceira em expansão com algumas das pessoas mais vulneráveis e exploradas do país" (Bateman, Sharife, 2014).

Os trabalhadores migrantes são recrutados para os empregos mais duros da indústria nas mesmas regiões empobrecidas do Sul e da África Austral onde o regime do apartheid costumava buscar mão de obra. Eles são expostos a práticas ilícitas de internediários inescrupulosos, traficantes, proprietários dos vilarejos e agiotas. Muitos são "irregulares", indocumentados e desprotegidos. Outros pertencem aos mais vulneráveis entre os muitos trabalhadores temporários "contratados" dos distritos de mineração, sendo estes, segundo Frankel (2013, p. 99), trabalhadores precários que, por medo de demissão, são "persuadidos" a entrar em "áreas perigosas onde os trabalhadores permanentes não vão ... e não têm de se submeter à legislação existente".

Os trabalhadores migrantes constituem, relata o autor, uma proporção cada vez maior dos trabalhadores contratados. Suas condições reais vão depender da "inescrupulosidade dos intermediários e usuários finais, da

\footnotetext{
${ }^{19}$ Registrada em Londres, com sua base operacional em Joanesburgo.
} 
natureza da demanda no mercado, da disponibilidade de homens, mulheres e crianças desesperados para trabalhar sob quaisquer circunstâncias e, em última análise, da capacidade do Departamento de Trabalho para monitorar suas próprias leis e regulamentos". A dependência de redes criminosas de traficantes, locais ou internacionais, de práticas severas de agiotas a nível comunitário, de cobradores criminosos de dívidas e de rígidos proprietários de terras, os obriga a uma "escravidão" por dívidas e a uma condição de trabalho de facto não-livre. Isso significa um estado de insegurança e coerção para muitos trabalhadores locais, bem como para migrantes sul-africanos. Porém, são os migrantes transfronteiriços os que estão particularmente ameaçados devido à sua residência condicionada e muitas vezes "ilegal". O emprego de mão de obra predominantemente masculina, como acontecia no apartheid e no regime colonial, colhe hiper-lucros através do subsídio de salários "sub-mínimos" pelo trabalho produtivo e reprodutivo não remunerado das mulheres em zonas rurais pobres de migrantes. As mulheres vítimas de tráfico de pessoas têm escassas oportunidades de emprego e muitas vezes acabam envolvidas na prostituição nas favelas ao redor das minas. Assim, os sistemas de migração do colonialismo e do apartheid, construídos com mão de obra precária hiperexplorada e não-livre, são reproduzidos nas condições informais atuais.

\section{Xenofobia - um estranho fruto da democracia}

Ao lado dos atos de solidariedade trabalhista, neste novo e justo mundo de "flexibilidade", surgem conflitos com base na etnia e na nacionalidade, tanto na indústria de mineração, quanto em outros setores econômicos e em todos os vilarejos. Esta situação reflete a renovada política de controle da força de trabalho, bem como as deterioradas estratégias sindicais na contenção do trabalho informal (Theron, 2010b). Em retrospectiva, o ano de 1994 foi um momento em que os líderes sindicais e ativistas começaram a se posicionar dentro das instituições do ANC e do Estado, e muitos trabalhadores negros subiram na escala ocupacional para assumir posições-chave nas hierarquias empresariais, o que, no entanto, também introduziu novas formas de controle corporativo. No período do apartheid, segundo Bezuidenhout e Buhlungu (2011), o controle era sujeito à contenção policial e à burocrática centralizada, enquanto o controle corporativo de hoje é dominado por uma diferenciação fragmentária dirigida pelo "mercado". Insere-se em uma economia política de re-racialização, com a cumplicidade da elite política negra e do movimento trabalhista.

Sob o disfarce de um discurso relativo à unidade da classe trabalhadora e ao "trabalho decente" o COSATU - deixando o sindicalismo comunitário para trás após o fim do apartheid -, de acordo com seus críticos, não conseguiu 
enfrentar as condições dos trabalhadores precarizados e dos moradores pobres, em geral, e dos migrantes, em particular (Fine, 2014; Barchiesi, 2011; Hlatshwayo, 2010; Buhlungu, 2010). Tomou, ao contrário, uma postura antes defensiva que ativa na organização dos migrantes transfronteiriços na África do Sul e em toda a região. Esses trabalhadores personificam o precariado sul-africano contemporâneo, devido à origem "estrangeira", à informalidade de seus meios de subsistência, à precária posição em termos de direitos e à exposição a práticas de vigilantismo e a abusos. Os sindicatos de trabalhadores, em geral, não se mostraram dispostos ou capazes de incluir em suas categorias esse precariado multiétnico de "nativos" e "estrangeiros" envolvidos em condições de trabalho informais e meios de subsistência vulneráveis (Barchiesi, 2011; Theron, 2010b; Fine, 2014). Os migrantes, em particular - conforme registrado por vários estudos críticos - raramente são vistos pelos sindicatos como atores sociais a serem incluídos em seus próprios espaços de luta mais ampla para mudar o equilíbrio de forças nos locais de trabalho e nos municípios. Portanto, os próprios sindicatos compartilham a responsabilidade pela persistência de uma espraiada xenofobia (Hlatshwayo, 2010; Fine, 2014).

O que convencionalmente aparece no debate sul-africano como "xenofobia" tem sido uma característica da era pós-apartheid desde o seu início e permanece uma realidade diária (Crush, 2000; Neocosmos, 2015). Um reflexo disso pode ser encontrado em uma estranha transição discursiva de "Kaffir", um termo pejorativo com raízes coloniais referente a negros sul-africanos sob o apartheid, para "Kwere Kwere", atualmente o principal termo depreciativo para o "estrangeiro" africano negro que possui um "sotaque peculiar", uma "cultura estranha" e uma pigmentação imaginada como sendo mais escura do que a dos sul-africanos negros "nativos". Longe de serem compartilhadas por todos os sul-africanos, as chamadas "atitudes xenófobas" têm se mostrado comuns e igualmente representadas entre "os pobres e os ricos, os empregados e os desempregados, os homens e as mulheres, os negros e os brancos, os conservadores e os radicais" (Crush, Pendleton, 2004, p. 2). No entanto, é a violência, repetidamente mortal, de negros contra negros e os saques que os migrantes sofrem em cidades negras pobres que veio a encarnar a imagem de uma virulenta "doença da xenofobia" (Neocosmos, 2015); ou, nas palavras de Fanon (1967), como sendo uma "negrofobia" branca internalizada (por exemplo, Mapokgole, 2014; Mbembe, 2015).

Alexandra - um dos municípios negros mais pobres da África do Sul - na fronteira com Sandhurst, uma das áreas residenciais mais ricas de Joanesburgo e, inclusive, o principal centro de negócios da África do Sul, com a bolsa de valores e mercado de ouro e diamante - continua sendo o símbolo concreto de tal estigma. Em maio de 2008, os ataques contra migrantes na região 
ganharam espaço nas manchetes da imprensa sul-africana e internacional. A partir dessa "faísca" espalhou-se rapidamente pelas cidades de todo o país, deixando mais de sessenta migrantes mortos, centenas de feridos, mais de 150.000 desabrigados, além de propriedades demolidas ou saqueadas. As vítimas eram sobretudo migrantes transfronteiriços, mas também grupos de trabalhadores migrantes internos sul-africanos, considerados como não pertencentes à comunidade local.

Os distritos abastados, como Sandhurst, e as míseras favelas, como Alexandra, apesar de brutalmente separados e serem, aparentemente, realidades distintas, hoje, e não menos do que durante o apartheid, estão intimamente conectados (Mingxitama, 2008, p. 197). De forma análoga a outras cidades globais, a riqueza historicamente acumulada em áreas como Sandhurst, Joanesburgo - que na época do apartheid era habitada apenas por brancos, enquanto hoje é co-habitada entre brancos e uma crescente classe de negros ricos - é produzida pelo duro trabalho de um extenso e multiétnico conglomerado laboral precário em vilarejos pobres como Alexandra. Ao mesmo tempo, os brancos e os negros de classe média alta foram os que "expressaram mais surpresa e desgosto pela violência que ocorrera" (Mapokgole, 2014, p. 45). Conforme Mapokgole, eles, rapidamente, "em um ato de má-fé, distinguiram-se dos moradores de Alexandra que cometeram os atos violentos", considerados por eles como "incompreensíveis". Portanto, infere a autora, isso deixou a violência em um vácuo "desconectado das vidas que eles, os ricos, viviam", absolvendo-os, desse modo, de qualquer responsabilidade.

Os massacres espraiados de 2008, chamados "pogroms" (Neocosmos, 2008), foram, na verdade, apenas um exemplo da violência infligida contra os corpos, os abrigos e as propriedades de trabalhadores migrantes, refugiados e vendedores ambulantes nos municípios sul-africanos. A xenofobia continua a ser uma realidade diária persistente e uma questão política cada vez mais dolorosa. Uma nova e extensa onda de violência começou em 2015 com ataques a pequenos comerciantes somalis em Soweto e continuou com ataques fatais contra estrangeiros que viviam e trabalhavam em Durban, alegadamente atiçados por declarações maliciosas dirigidas contra estrangeiros ao nível de administração regional e ministros da República. Enquanto sociedade infere o Fórum da Diáspora Africana (ADF, 2015) em sua carta de apelo ao Presidente da República - "estamos em uma situação pior do que em 2008, já que as atitudes e os discursos xenofóbicos penetraram nas instituições estatais e afetaram tanto a base quanto o vértice do estado".

A violência do pobre-contra-pobre da África do Sul foi interpretada, por vezes, como consequência da persistente desigualdade de raça e classe (Bond, Ngwane, Amisi, 2010). Outros, com referência a Franz Fanon e Steve 
Biko, descreveram a "xenofobia" de hoje como "vertigem do apartheid" (Matsinhe, 2011), como um fantasma do passado que representa "[algo] 'mais sombrio', uma vez que se poderia atacar um 'estrangeiro' sob o pretexto de ele ser 'escuro' demais - um ódio contra si mesmo por excelência" (Mbembe, 2015). A urgência de "exorcizar os demônios internos" (Landau, 2011, p. 2), no entanto, é mais do que o estado miserável de uma psique pós-colonial negra. Diz respeito a "rachaduras na ordem jurídica e no pacto social contemporâneos", com raízes na história da "política sul-africana". Isso se manifesta, argumentam Misago et alii (2009), em práticas burocráticas pós-apartheid sob a forma de rotular, marginalizar e separar populações, sendo os "não-nacionais" o "equivalente funcional" dos negros sul-africanos sob o antigo regime. Esta situação é, ademais, reproduzida e exacerbada por um clientelismo micropolítico nas comunidades locais que, sob certas condições, pode transformar essas profundas divisões entre "estrangeiros" e "nativos" em "recursos", através de violência e saques.

Gordon (2010), por sua vez, desenvolve um quadro explicativo sintético referente a leis, economia política e reivindicações a respeito dos privilégios de cidadania incorporados na hegemonia pós-apartheid vigente. Segundo o autor, a "divisão entre cidadão e estrangeiro" está fixada mediante a discriminação jurídica, ecoada no senso comum do discurso político, na mídia e na tradição popular compartilhada em todo o país. No entanto, tudo isso funciona não apenas para destacar a "diferença" cultural ou genética, mas, sobretudo, para "criar a vulnerabilidade particularmente intensa que deixa os migrantes expostos a formas de violência e exploração" (Gordon, 2010, p. 7). Para desempenhar essa função, "esses migrantes devem estar despojados das normas constitucionais que foram criadas para proteger as liberdades individuais". Trata-se de uma condição forjada através de um "'estado de exceção', interpretado como um direito do Estado à sua autodefesa". A "xenofobia" surge nessa narrativa como uma precondição e uma ferramenta da engenharia de um regime jurídico-político de uma multidão "xenoracial" de "novos negros" 20 , que são trabalhadores, pobres e migrantes. Isso é evidenciado pelos abusos diários a migrantes em bairros negros e, cada vez mais, nos guetos do centro das cidades de Pretória, Joanesburgo e Durban. Esses migrantes se tornam vitimizados, enquanto as lutas pela cidadania, pelos direitos sociais e econômicos, pelos benefícios e acesso a serviços públicos prometidos na transição para a democracia se tornam cada vez mais duras nos distritos expostos ao desemprego, ao subemprego, à informalização dos

\footnotetext{
${ }^{20}$ Sivanandan (2001) cunhou em "Poverty is the new Black" a noção de "xeno-racismo" numa tentativa de incluir uma análise da situação da nova população pobre, estigmatizada e hiperexplorada de europeus orientais fenotipicamente brancos na teoria britânica sobre raça e classe, tradicionalmente focada em migrantes pós-coloniais "de cor".
} 
meios de subsistência, à mercantilização dos serviços públicos e à armadilha da dívida de uma indústria de microcrédito que destrói "as escassas reservas de confiança comunitária intra e inter-étnica, de cooperação mútua, reciprocidade e solidariedade" (Bateman, 2014, p. 94). Assim sendo, de acordo com Desai e Walsh (2010, p. 12), o sistema racista do apartheid, que "maximizava a mão de obra barata com pouco ônus financeiro para o Estado", foi suplantado por "um contingente de mão de obra barata sem direitos dentro de um contingente de mão de obra barata de negros sul-africanos". Trata-se dos alienados "membros de uma sociedade, sem o apoio do Estado ... policiados através da violência, tanto do Estado quanto de outros sul-africanos pobres que se veem como portadores (e possíveis beneficiários) de certos direitos e concessões".

Uma multidão de atores marginalizados, que compartilha a falta de proteção, a extrema vulnerabilidade e a dependência de obscuras disposições institucionais, pode parecer um terreno fértil para a proliferação de uma sociedade com a "psicologia da violência", que opera "com base no elo mais fraco" (Mingxitama, 2008, p. 196). No entanto, as políticas discriminatórias, que constroem a precariedade para a flexploitation, podem "levar a todo tipo de reação, desde a autoimolação até a luta de classe" (Neocosmos, 2015). Com efeito, apesar dos esforços do Estado do apartheid para criar e explorar divisões étnico-raciais, os trabalhadores migrantes da ampla região da África meridional, ao lado dos "nativos estrangeiros" (Neocosmos, 2006) desnacionalizados, participaram ativamente das lutas contra o apartheid. É exatamente este o enigma no centro do quebra-cabeça xenofóbico de onde desenvolver uma análise complexa, sustenta Neocosmos (2006). A partir desta perspectiva, a xenofobia de hoje emerge como o estranho fruto da "Revolução Nacional Democrática". Ela engloba uma discrepância entre, por um lado, um discurso pan-africano amplamente mobilizador e uma ideia ativista inclusiva de cidadania desenvolvidos durante a luta contra o apartheid junto a uma ampla comunidade ancorada em um sindicalismo comercial como vanguarda; e, por outro, uma concepção xenofóbica e restrita da cidadania que marca a ideologia pós-apartheid de construção da nação. Aqui, em nome dos direitos humanos e dos acertos de conta com as injustiças históricas, o fantasma do passado, na narrativa da Nação Arco-Íris sobre construção nacional, é representado não como xenofobia, mas como migração, associada, per se, com o maligno sistema de trabalho forçado do apartheid.

\section{Para onde vai a "revolução inacabada"?}

A incessante violência xenofóbica evidenciou as contradições de uma crise política e social cada vez mais profunda e impulsionou as críticas sobre a disjunção entre sonho e realidade. A adoção do neoliberalismo "roubou o sonho sul-africano", assevera Satgar (2011). As duas últimas décadas da 
integração da República aos circuitos globais de acumulação, conforme esse autor, puseram fim à credibilidade do discurso positivo pós-apartheid de um "excepcionalismo sul-africano". A África do Sul tornou-se um dos muitos "laboratórios" do "discriminatório neoliberalismo africano" (Satgar, 2012); um "terrível mundo de... barbárie capitalista", marcado, por "brutais conflitos, racistas e xenófobos, de todos contra todos", lamenta Alexander (2010) em "South Africa: an unfinished revolution". No entanto, a África do Sul continua a ser, de alguma forma, "excepcional" no contexto mais amplo regional e africano; isto é, em seu papel de hegemonia subimperial herdada do Estado do apartheid, embora com uma nova roupagem (Bond, 2012a; Samson, 2009). A República apresenta-se como uma potência econômica regional na nova "Corrida à África", do século XXI, com demandas por "mudança de regime" como contrapartidas à política de investimento e empréstimos. É uma "Fortaleza África do Sul" que reformulou um sistema migratório e de trabalho não-livre de origem colonial em toda a África meridional e a África subsaariana (Evans, 2010). É, ao mesmo tempo, uma sociedade onde os imaginários xenófobos representam a concretização de uma ideologia de excepcionalismo, que descreve "os sul-africanos como superiores ao resto do continente ... [e] os outros seres humanos que exibem diferenças da suposta norma estabelecida como forasteiros para a comunidade e, portanto, como inimigos da nação, que podem, então, se tornar alvos legítimos de violência" (Neocosmos, 2015).

A sangrenta quinta-feira de Marikana - rotulada como "o Sharpeville da democracia" (Frankel, 2013) - pode ser vista como um "divisor de águas" (CASAC, 2012) na curta história da África do Sul pós-apartheid; "uma desilusão final", como previsto por Alexander (2010). Revelou a necessidade de se entender a crise política e social da África do Sul no contexto de uma crise da globalização neoliberal, em geral, e da estratégia de acumulação pós-apartheid, em particular, com sua persistente dependência do complexo mineral e energético (Mohamed, 2007), sendo este inserido em um "triângulo do tormento" corporativista (Alexander et alii, 2013, p. 146), cujo perímetro circunscreve o extrativismo em um negócio corporativo globalizado, uma elite política que dirige um aparato de segurança assustador e um consagrado e distorcido movimento sindical. A partir dessa perspectiva, podemos ver Marikana como o presságio de uma nova fase cada vez mais violenta na busca de uma estratégia de acumulação viável, que, por enquanto, não possui nenhuma perspectiva de consenso. Entretanto, em uma abordagem mais otimista, numa perspectiva polanyiana $(1957,(1944))$, podemos também reconhecer uma crise da estratégia de acumulação neoliberal acompanhada por um "contramovimento" multifacetado e popular que contesta a acumulação através da expropriação que destruiu o sonho e a luta por justiça social, bem-estar e dignidade impregnados na Revolução Nacional Democrática. 
Para o movimento dos trabalhadores, a trajetória neoliberal significou "um paradoxo da vitória" (Buhlungu, 2010). De acordo com Fine (2014, p. 336), essa situação reflete uma desconcertante trajetória pós-apartheid, com o COSATU inicialmente conseguindo incorporar instituições socialdemocratas do mercado de trabalho na governança econômica, mas perdendo a batalha para buscar políticas fiscais e monetárias correspondentes. Enquanto os sindicatos são enfraquecidos pela sua cumplicidade na reestruturação corporativa e na transição da elite, e enquanto o prometido início do trabalho digno e da cidadania inclusiva é ofuscado pela pobreza, o trabalho precário e a servidão por dívida, grandes setores dos trabalhadores sindicalizados, incluindo muitos trabalhadores migrantes presos nos mais árduos empregos em troca de salários insignificantes, assumiram posturas radicais em decorrência dos eventos em Marikana. Uma subsequente tempestade de agitações trabalhistas em todo o país resultou em uma profunda divisão no movimento de trabalhadores, que por fim se manifestou através da dramática fragmentação do COSATU, cujas consequências políticas permanecem indefinidas (Bell, 2015; Jim, 2015).

Enquanto isso, um precariado informal permanece às margens de um movimento trabalhista que liquidou seu célebre "sindicalismo comunitário", outrora enraizado entre os municípios pobres. Em seu lugar, uma "cidadania insurgente" (Miraftab, 2009) irrompeu, adotando "os pobres" (Desai, 2002) como um novo sujeito político. Manifesta-se como uma resistência micropolítica diária, com milhares de protestos contra a privatização das moradias, os despejos forçados e a mercantilização de necessidades básicas, como eletricidade ou água. Em contraste com os "espaços convidados" para a "deliberação das partes interessadas" entre a sociedade civil, as empresas e o Estado, os pobres criam seus próprios "espaços inventados", como locais para protestos e ações comunitárias não solicitadas (Miraftab, 2009). Esse movimento informal do precariado sul-africano, à margem de qualquer direito substancial e para além do controle estatal, merece, na opinião de Neocosmos $(2011)^{21}$, a honrosa designação de uma "sociedade incivil", muitas vezes atingida por balas de borracha, spray de pimenta e acusações criminais (por exemplo, UPM, 2013). Pode ser entendida como apartada de uma "sociedade civil" de OSCs (Organizações da Sociedade Civil) e ONGs (Organizações Não Governamentais) orientadas pela conformidade a uma agenda de direitos humanos legalista e despolitizada e marcadas pela incorporação na governança neoliberal como provedores de serviços ou como "think tanks" financiados pelo Estado ou pelos doadores internacionais. Isso implica uma evidente divisão, concluem Fioramonti e Fiori (2010, p. 35), entre "ONGs com bons recursos que gozam de apoio popular bastante limitado (e que muitas vezes

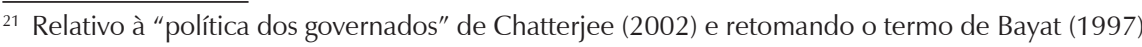
referente à "política de pessoas informais". 
se abstêm de assumir uma posição política explícita) e espraiados movimentos de base, com poucos recursos e forte ênfase nos direitos socioeconômicos, que se tornaram cada vez mais barulhentos em questões de justiça social, sem hesitar em entrar no terreno político".

Não importa se concordamos com a controversa definição de precariado de Guy Standing (2011), como sendo uma nova e perigosa classe. Podemos, no entanto, estar de acordo com a afirmação de que é realmente perigosa. Mas é "perigosa" no sentido que é uma "sociedade incivil", flutuante e, no entanto, genuinamente política, situada nas fronteiras da informalidade e fora do alcance de uma governança que coopta, disciplina e despolitiza uma "sociedade civil" autorizada (Neocosmos, 2011). Assim, a criativa "informalização desde baixo" pelos pobres pode comportar mais do que um ajuste flexível e afirmativo à "informalização corporativa desde cima"; uma transmutação de facilitador de "flexploitation" para uma "política de pessoas informais" (Bayat, 1997) que resiste à "tirania do mercado" (Bourdieu, 1999a).

Desta forma, uma multifacetada "sociedade incivil" sul-africana envolve, para além de voláteis e localizados protestos no dia a dia, uma série de movimentos sociais articulados. Entre eles, o Movimento dos Desempregados (UPM, em inglês) - inspirado no sonho de Martin Luther King de construir uma aliança entre os pobres coast-to-coast - e o Movimento Sem-terra - membro do movimento internacional de Via Campesina. Segundo o presidente da UPM, Ayanda Kota (2012), diante da "farsa do apartheid econômico" da atual conjuntura histórica, que substitui a "tragédia do apartheid", um novo movimento social dos pobres precisa se desenvolver. Exigirá estratégias contra-hegemônicas complexas e de longo prazo, de baixo para cima, para a transformação revolucionária da "sociedade inteira", a "participação do povo" e o "compartilhamento do poder político e do controle sobre os recursos". Tais estratégias - explica Kota (2014) - devem combinar a confiança informal cotidiana com uma "segunda tarefa": criar uma mais ampla subjetividade de oposição. Isso só acontecerá ligando a ação informal do dia a dia, que visa à melhoria dos meios de subsistência (começando, por exemplo, com padarias comunitárias, creches e jardins urbanos) com a promoção de "uma consciência política e social, e a construção de um movimento de massa", potencialmente em aliança com um rejuvenescido movimento trabalhista.

Esses movimentos "dos pobres" surgiram em 2015 e foram apoiados pelo crescente recrudescimento de um movimento estudantil rebelde que anunciava "o ressurgimento do poder do povo" (Naicker, 2015). Sob a bandeira de \#RodhesMustFall e com referência à literatura radical que inspirou a luta contra o apartheid, como Fanon, Biko e Cabral - esse movimento recuperou a memória da gélida "tempestade" do colonialismo que assolou a população negra e contestou a suposta submissão da elite política de hoje 
ao legado colonial (Kunene, 2015). Sob a insígnia de \#FeesMustFall, passou a contestar as desvantagens de classe e raça que continuam a permear o sistema educacional pós-apartheid.

Uma multifacetada e insurgente cidadania pode, às vezes, possuir um componente "xenofóbico", mas, muitas vezes, encarna uma organização cívica em solidariedade com os não-cidadãos africanos, destacando o aspecto comunitário para além da origem ou da nacionalidade e, portanto, contestando políticas de cunho xenofóbico (EAC, 2008; Payn, 2015). A multidão insurgente da África do Sul também conta com organizações vigorosas e um movimento crítico nascido das comunidades da diáspora africana, que levantam suas vozes contra a Afrofobia, em defesa dos meios de subsistência e por uma África do Sul não racial e inclusiva (por exemplo, ADF, 2015). No entanto, as vozes de uma desafiadora "migritude" (Willén, 2015), segundo Desai e Walsh (2010), são muitas vezes marginalizadas, em favor de recomendações civis ao Estado por meio de refinados relatórios financiados por organizações internacionais de direitos humanos; Estado esse que, embora oficialmente denuncie essa situação, brinca com o fogo atiçando e explorando a violência xenofóbica.

Assim, enquanto as profundas divisões sociais da África do Sul estão rumando para um ponto crítico e um crescente abismo de desconfiança se abriu entre as lideranças do ACN e seu eleitorado, a xenofobia constitui um estratagema de um bloco de poder hegemônico na atual disputa política. Como em outros lugares, e não menos que nos oscilantes cenários políticos de uma "Europa completa" (Holmes, 2000), a política de nacionalismo endógeno tornou-se a parceira político-ideológica do "capitalismo rápido", em substituição de uma política social subvertida pela mercantilização. Marcar as fronteiras do pertencimento constitui um estratagema populista para aumentar a legitimidade e conter a crise social através da cooptação, do redirecionamento, da pacificação e da exploração de uma multifacetada, mas politicamente volátil, revolta de pessoas pobres (Hart, 2013). Isso constitui uma articulação sul-africana específica do problema geral da transição da elite na pós-colonialidade, assim como levantada por Fanon (1967); uma reprodução paradoxal das estruturas profundas do apartheid, através de uma recirculação mitológica do imaginário da "Revolução Nacional Democrática" por meio da hegemônica coalizão, na gestalt mutante de um integralismo organicista. Autoriza-se, desta forma, uma re-tradicionalização da sociedade e apresenta-se um patriarcalismo de estilo pós-moderno e um conspícuo consumo entre as elites políticas como modelos para as famílias pobres e negras (Hart, 2013).

No entanto, a coalizão tripartite que governa é dominada por profundos conflitos internos e tem sido contestada por importantes e emergentes projetos políticos contra-hegemônicos, que crescem das profundas fraturas no interior 
da própria hegemonia política pós-apartheid, fora de um ANC desencantado e de um movimento trabalhista traumatizado ${ }^{22}$. Nesta junção de crise social e política, podem estar contados os dias afortunados da singular aliança de classe em que a hegemonia sul-africana pós-apartheid foi fundada; um momento de crise em que o velho está morrendo e, aparentemente, o novo ainda não pode nascer ${ }^{23}$. Levanta-se, portanto, a questão de se as "esperanças e perspectivas" de um pacto social renovado serão, supostamente, levadas adiante no interior da coalizão política tripartite original - com a promessa de uma "fase mais radical" da revolução democrática nacional que está por vir (Umsebenzi, 2015) - ou, em alternativa, por forças nascentes de contestação, que a desafiam desde fora. Seja como for, o trabalho precário, os movimentos de pessoas pobres, a migração e a xenofobia são estratagemas cruciais do momento. Dizem respeito à necessidade de construir alianças inclusivas com movimentos de um precariado composto por "nativos" e "estrangeiros" em uma sociedade onde a política da xenofobia e uma distorcida narrativa nacionalista, que interpreta a migração como o espectro do passado do apartheid da África do Sul, se tornaram uma cortina de fumaça que encobre a "revolução inacabada" da atualidade.

\section{Referências bibliográficas}

ADF. Open Letter to President Jacob Zuma. African Diaspora Forum. 2015. Available at: <http://adf.org.za/?q=node/57>.

ALEXANDER, Neville. South Africa: An unfinished revolution? The fourth Strini Moodley Annual Memorial Lecture, held at the University of KwaZulu-Natal on May 13, 2010.

ALEXANDER, Neville. Thoughts on the New South Africa. Auckland Park: Jacana, 2013.

ALEXANDER, Peter; SINWELL, Luke; LEKGOWA, Thapelo; MMOPE, Botsang; XEZWI, Bongani. Marikana. A View from the Mountain and a Case to Answer. Auckland Park: Jacana Media, 2013.

ALTMAN, Miriam. Low Wage Work in South Africa. Paper presented to: IZA/World Bank Conference on Employment \& Development. Berlin, May 25 - 27, 2006.

AMIT, Roni. Queue Here for Corruption. Measuring Irregularities in South Africa's Asylum System. Pretoria and Johannesburg: Lawyers for Human Rights and African Centre for Migration and Society, 2015.

ANC. The Freedom Charter. As adopted at the Congress of the People, Kliptown, on 26 June 1955. 1955. African National Congress. Available at: <http://www.anc.

\footnotetext{
${ }^{22}$ Nomeadamente os Economic Freedom Fighters (um partido fundado pelo antigo presidente da Liga da Juventude do ANC, Julius Malema, que foi expulso do ANC depois de ter criticado a sua liderança por cumplicidade no cadinho de Marikana) e a United Front (uma coligação de forças esquerdistas apoiadas em sindicatos que deixaram de seguir a linha do COSATU).

${ }^{23}$ Aludindo ao ilustre ditado de Gramsci.
} 
org.za/show.php?id=72>.

ARMAH, Ayi Kwei. The Beautiful Ones are not yet Born. Oxford \& Johannesburg: Heineman, 1968.

BALIBAR, Étienne. We, the People of Europe? Reflections on Transnational Citizenship. Princeton, NJ and Oxford: Princeton University Press, 2004.

BARCHIESI, Franco. Informality and Casualization as Challenges to South Africa's Industrial Unionism: Manufacturing Workers in the East Rand/Ekurhuleni Region in the 1990s. African Studies Quarterly, v. 11, n. 2-3, p. 67-85, 2010.

BARCHIESI, Franco. Precarious Liberation. Workers, the State and Contested Social Citizenship in Postapartheid South Africa. New York and Durban: Suny Press and the University of KwaZulu-Natal Press, 2011.

BATEMAN, Milford. South Africa's post-apartheid microcredit-driven calamity. Law, Democracy and Development, v. 18, p. 92-135, 2014.

BATEMAN, Milford; SHARIFE, Khadija. The destructive role of microcredit in postApartheid South Africa. In: BATEMAN, Milford; MACLEAN, Kate (eds.). Seduced and Betrayed: Exposing the Contemporary Microfinance Phenomenon. Santa Fe, NM: SAR Press, 2014.

BAYAT, Asef. Un-civil society: the politics of the "informal people". Third World Quarterly, v. 18, n. 1, p. 53-72, 1997.

BELL, Terry. 'SACP's flag is palest pink'. 2015. Available at: < http://groundup.org. za/article/sacps-flag-palest-pink_3156>.

BENJAMIN, Paul. The Persistence of Unfree Labour: The Rise of Temporary Employment Agencies in South Africa and Namibia. In: FUDGE, Judy; STRAUSS, Kendra (eds.). Temporary work, agencies, and unfree labour: Insecurity in the new world of work. London \& New York, NY: Routledge: 2013a, p. 118-43.

BENJAMIN, Paul. Law and practice of private employment agency work in South Africa. Geneva: ILO, 2013b.

BEZUIDENHOUT, Andries; KENNY, Bridget. The Language of Flexibility and the Flexibility of Language: Post-Apartheid South African Labour Market Debates. SWOP, 2000. Available at: <http://www.swopinstitute.org.za/node/24>.

BEZUIDENHOUT, Andries; BUHLUNGU, Sakhela. From Compounded to Fragmented Labour: Mineworkers and the Demise of Compounds in South Africa. Antipode, v. 43, n. 2, p. 237-63, 2011.

BEZUIDENHOUT, Andries; GODFREY, Shane; THERON, Jan. Non-standard employment and its policy implications. Johannesburg and Cape Town: Sociology of Work Unit, University of the Witwatersrand and Labour and Enterprise Project, University of Cape Town, 2004.

BOND, Patrick. Elite Transition: From Apartheid to Neoliberalism in South Africa. London \& Ann Arbor: Pluto Press, 2000.

BOND, Patrick. South Africa and Global Apartheid: Continental and International Policies and Politics. Uppsala: Nordiska Afrikainstitutet, 2004. 
BOND, Patrick. South Africa Embraces Corporate Welfare: Mega Deal Subsidies Over Services for the Poor. Multinational Monitor, v. 27, n. 5, 2006.

BOND, Patrick. Subimperialism as lubricant of neoliberalism. South Africa's emergence from the apartheid laager. Research Network on Global Governance and the Emerging Global South conference on Rising Powers and the Future of Global Governance. Panel on 'Resistance and Civil Society. University of Sussex, 16.05.2012a.

BOND, Patrick. In South Africa, the poor pay the electricity bill of the world's largest mining company. EJOLT, 2012b. Available at: < http://www.ejolt.org/2012/10/insouth-africa-the-poor-pay-the-electricity-bill-of-the-worlds-largest-mining-company/> .

BOND, Patrick. Debt, uneven development and capitalist crisis in South Africa: From Moody's macroeconomic monitoring to Marikana's microfinance mashonisas. Third World Quarterly, v. 34, n. 4, p. 569-92, 2013.

BOND, Patrick. "Talk left, walk right" in South African social policy. Tokenistic extension of state welfare versus bottom-up commoning of services. 2014. Available at: <http://sds.ukzn.ac.za/files/2014-02-19\%20Bond\%20SA\%20 social\%20policy.pdf $>$.

BOND, Patrick; NGWANE, Trevor; AMISI, Baruti. Xenophobia and civil Society: Why did it happen? Durban: University of KwaZulu-Natal Centre for Civil Society, 2010.

BOURDIEU, Pierre. Acts of Resistance: Against the Tyranny of the Market. New Press, 1999a.

BOURDIEU, Pierre. The Weight of the World: Social Suffering and Impoverishment in Contemporary Society. Cambridge: Polity Press, 1999b.

BRAMBLE, Tom. Social movement unionism since the fall of Apartheid: The case of NUMSA on the East Rand. In: BRAMBLE, Tom; BARCHIESI, Franco (eds.). Rethinking the Labour Movement in the 'New South Africa'. Aldershot: Ashgate, 2003.

BUHLUNGU, Sakhela. A Paradox of Victory: COSATU and the Democratic Transformation in South Africa. Scotsville: University of KwaZulu-Natal Press, 2010.

CASAC. Statement by the Council for the Advancement of the South African Constitution, on the impact of Marikana on South Africa's constitutional order. Polity org.za. 2012. Available at: < http://www.polity.org.za/article/sa-statement-bythe-council-for-the-advancement-of-the-south-african-constitution-on-the-impactof-marikana-on-south-africas-constitutional-order-03102012-2012-10-03>.

CHATTERJEE, Partha. The Politics of the Governed. New York (NY): Columbia University Press, 2002.

COHEN, Robert. The Marikana tragedy: South Africa's social contract with its working poor breaks down. Inroads, n. 32, 2013.

COTTLE, Eddie; ROMBALDI, Mauricio. Lessons from South Africa's FIFAWorld Cup. Brazil and its Legacy for Labour. Wits: The Global Labour University, 2014.

$\mathrm{CRUCH}$, Jonathan. South Africa: New nation, new migration policy. Migration Information Source. 2003. Available at: <http://www.migrationinformation.org/ profiles/>. 
CRUSH, Jonathan. Fortress South Africa and the deconstruction of apartheid's migration regime. Geoforum, v. 30, n. 1, p. 1-11, 1999.

CRUSH, Jonathan. The Dark Side of Democracy: Migration, Xenophobia and Human Rights in South Africa. In: APPLEYARD, Reginald (ed.). The Human Rights of Migrants. Offprint of International Migration, v. 38, n. 6, Special Issue 3, 2000.

CRUSH, Jonathan; PENDLETON, Wade. Regionalizing Xenophobia? Citizen Attitudes to Immigration and Refugee Policy in Southern Africa. 2004. Available at: < https://mww.africaportal.org/documents/18066/Regionalizing_Xenophobia.pdf>.

DESAI, Ashwin; WALSH, Shannon. Knowledge \& Power in South Africa: Xenophobia and survival in the post-apartheid state (quotes from on line version at academia. edu). In: CHOUDRY, Azis; KAPOOR, Dip (eds.). Global Perspectives on Social Movements and Knowledge Production: Learning from the ground up. New York: Palgrave MacMillan, 2010.

DESAI, Ashwin. We Are the Poors. Community Struggles in post-apartheid South Africa. New York: Monthly Review Press, 2002.

DUBE, Phephelaphi. The "Undesirable" Immigration Regulations 2014. Cape Town: Centre for Constitutional Rights, 2014.

EAC. Evicted South Africans Rally in Support of Immigrants. Grassroots International. 2008.

EID, Haidar. An independent homeland or bantustan in disguise? The Electronic Intifada. 2015. Available at: < https://electronicintifada.net/content/independenthomeland-or-bantustan-disguise/9905>.

EVANS, Jessica. The neoliberal turn in the SADC. Regional integration and disintegration. Nokoko, n. 1, Fall 2010.

FANON, Frantz. Black Skin, White Masks. New York, NY: Growe, 1967.

FINE, Janice. Migration and Migrant Workers in the Post-Apartheid Era. Global Labour Journal, v. 5, n. 3, p. 330-346, 2014.

FIORAMONTIA, Lorenzo; FIORI, Antonio. Civil Society after Democracy: The Evolution of Civic Activism in South Africa and Korea. Journal of Civil Society, v. 6, n. 1, p. 23-38, 2010.

FIRST, Ruth. The Gold of Migrant Labour. Review of African Political Economy, n. 25, p. 5-21, 1982.

FORREST, Kally. Marikana was not just about migrant labour. Mail \& Guardian. 2013. Available at: < http://mg.co.za/article/2013-09-13-00-marikana-was-notjust-about-migrant-labour $>$.

FRANKEL, Philip. The politics of passes: Control and change in South Africa. The Journal of Modern African Studies, v. 17, n. 2, p. 199-217, 1979.

FRANKEL, Philip. Between the Rainbows and the Rain. Marikana, Migration, Mining, and the Crisis of Modern South Africa. Johannesburg: Agency for Social Reconstruction, 2013.

GALABUZI, Grace-Edward. Canada's Economic Apartheid: The Social Exclusion of Racialized Groups in the New Century. Toronto: Canadian Scholars' Press Inc., 2006. 
GENTLE, Lenny. Poverty and social movements. In: MAHARAJ, Brij; DESAI, Ashwin; BOND, Patrick (eds.). Zuma's Own Goal. Losing South Africa's 'War on Poverty'. Asmara: Africa World Press, 2011, p. 359-380.

GILROY, Paul. There Ain't No Black in the Union Jack. London: Hutchinson, 1987.

GOLDRING, Luin; LANDHOLT, Patricia. Caught in the Work-Citizenship Matrix: The Lasting Effects of Precarious Legal Status on Work for Toronto Immigrants. Globalizations, v. 8, n. 3, p. 325-41, 2011.

GORDON, Steven. Migrants in a 'State of Exception. Transcience Journal, v. 1, n. 1, p. 3-21, 2010.

GREENFIELD, Daniel. Frontpage. 2014. Available at: < http://www.frontpagemag. com/2014/dgreenfield/saudi-arabia-the-middle-easts-real-apartheid-state/>.

HABIB, Adam. South Africa's Suspended Revolution. Hopes and Prospects. Athens, OH: Ohio University Press, 2013.

HART, Gillian. Rethinking the South African Crisis: Nationalism, Populism, Hegemony. Geographies Justice and Social Transformation, 20, Athens, GA: University of Georgia Press, 2013.

HARVEY, David. A Brief History of Neoliberalism. Oxford: Oxford University Press, 2005.

HENRARD, Kristin. The internally displaced in South Africa (1)The strategy of forced removals and apartheid. Jura Falconis, v. 32, n. 4, p. 491-522, 1995-96.

HIETALAHTI, Johanna. Trade-Offs, Rights and Responsibilities in the Business of Microcredit. A case Study from South Africa. Academic Dissertation, Helsinki: Department of Political and Economic Studies, 2013.

HLATSHWAYO, Mondli. COSATU's attitudes and policies towards external migrants. In: BUHLUNGU, Sakhela; TSHOAEDI, Malehoko (eds.). COSATU's Contested Legacy: South African Trade Unions in the Second Decade of Democracy. Cape Town: HSRC Press: 2010, p. 228-258.

HOLMES, Douglas R. Integral Europe: Fast-Capitalism, Multiculturalism, Neofascism. Princeton, NJ and Oxford: Princeton University Press, 2000.

HUNT, Jemini. Brazil is not just samba, sun and indulgence. The poor remain in slavery. The Guardian, 26.08.2007. Available at: <http://www.theguardian.com/ world/2007/aug/26/brazil.theobserver>.

JEEVES, Alan H. Migrant Labour in South Africa's Mining Economy. The Struggle for the Gold Mines' Labour Supply 1890-1920. Kingston and Montreal: McGillQueen's University Press, 1985.

JIM, Irvin. Can the Cosatu Congress save the workers federation from collapse?', Daily Maverick. 2015. Available at: <http://www.dailymaverick.co.za/ opinionista/2015-11-15-can-the-cosatu-congress-save-the-workers-federationfrom-collapse/\#.VlJOP7-Btc8>.

JOHNSON, David. Chapter 11: Migrancy and Thabo Mbeki's African Renaissance. In: GUPKA, Suman; OMONIYI, Tope (eds.). The Cultures of Economic Migration. Aldershot: Ashgate, 2007. 
KEEGAN, Timothy. Colonial South Africa and the origin of the racial order. Cape Town: David Philip, 1982.

KIHATO, Caroline; LANDAU, Loren B. The Uncaptured Urbanite. Migration and State Power in Johannesburg. Johannesburg: University of the Witwatersrand. Forced Migration Studies Programme, 2006.

KOK, Pieter, GELDERBLOM, Derik; OUCHO, John O.; VAN ZYL, Johan (eds.). Migration in South and Southern Africa. Dynamics and Determinants. Cape Town: HSRC Press, 2006.

KOTA, Ayanda. UPM to feed own struggle. Activate. Rhodes University's Independent Student News Source. 2012.

KOTA, Ayanda. Some lessons for South Africa's sectarian middle-class lefties. GroundUp. 2014. Available at: <http://groundup.org.za/article/some-lessonssouth-africas-sectarian-middle-class-lefties_2506>.

KUNENE, Phindile. Shelter after our people's rainstorm: A post-Rhodes response to Thami Mazwai. The Daily Maverick, 16.04.2015.

LANDAU, Loren B. Introducing the demons. In: LANDAU, Loren B. (ed.). Exorcising the Demons within. Xenophobia, Violence and Statecraft in Contemporary South Africa. Tokyo, New York, Paris: United Nations University Press, 2011.

LAZARIDIS, Gabriella; PSIMMENOS Jordanis. Migrant flows from Albania to Greece: Economic, social and spatial exclusion. In: BALDWIN, Edwards; ARANGO, Joaquin (eds.). Immigrants and the Informal Economy in Southern Europe. London and Portland: Macmillan, 2000.

LEIBBRANDT, Murray; WOOLARD, Ingrid; MCEWEN, Hayley; KOEP, Charlotte. Employment and Inequality Outcomes in South Africa. Cape Town: School of Economics, University of Cape Town, 2009.

MAHARAJ, Brij; DESAI, Ashwin; BOND, Patrick (eds.). Zuma's Own Goal. Losing South Africa's 'War on Poverty'. Asmara: Africa World Press, 2011.

MAHARAJH, Rasigan. Innovating Beyond Racial Capitalism: A Contribution Towards the Analysis of the Political Economy of Post-Apartheid South Africa. Lund: Lund University Press, 2011.

MAMDANI, Mahmood. Citizen and Subject: Contemporary Africa and the Legacy of Late Colonialism. Princeton, NJ: Princeton University Press, 1996.

MANDELA, Nelson. Ubuntu Told by Nelson Mandela, YouTube, 2012. Available at: $<$ https://www.youtube.com/watch?v=HED4h00xPPA $>$.

MAPOKGOLE, Reshoketswe B. There Is No Black In The Rainbow (Nation): A Bikoist and Fanonian Approach To Understanding "Xenophobic" Violence In South Africa. London \& Cape Town: Trinity College, 2014.

MASSEY, Douglas; DENTON, Nancy. American Apartheid: Segregation and the Making of the Underclass. Cambridge Massachusetts: Harvard University Press, 1993.

MATSINHE, David M. Apartheid Vertigo. The Rise in Discrimination against Africans in South Africa. Interdisciplinary Research Series in Ethnic, Gender and Class Relations, Farnham: Ashgate, 2011. 
MBEKI, Moeletsi. Architects of Poverty. Why African Capitalism Needs Changing. Johannesburg: Picador Africa, 2009.

MBEMBE, Achille. Achille Mbembe writes about Xenophobic South Africa. Africa is a Country. 2015. Available at: <https://africasacountry.com/2015/04/achillembembe-writes-about-xenophobic-south-africa > .

MCDONALD, David A. Electric Capitalism: Recolonising Africa on the Power Grid. London: Earthscan Ltd, 2012.

MCDONALD, David A.; RUITERS, Greg. Careful what you ask for. State-led alternatives to privatisation. In: MCDONALD, David A.; RUITERS, Greg (eds.) Alternatives to Privatization. Public Options for Essential Services in the Global South. London: Routledge, 2012.

MINGXITAMA, Andile. We are not all like that. Race, class and nation after apartheid. In: HASSIM, Shireen; KUPE, Tawana; WORBY, Erik (eds.). Go Home or Die Here. Johannesburg: Wits University Press, 2008.

MIRAFTAB, Faranak. Neoliberalism and casualization of public sector services: The case of waste collection services in Cape Town, South Africa. International Journal of Urban and Regional Research, v. 28, n. 2, p. 874-92, 2004.

MIRAFTAB, Faranak. Insurgent planning: Situating radical planning in the global south. Planning Theory, v. 32, n. 8, p. 32-50, 2009.

MISAGO, Jean Pierre; LANDAU, Loren B.; MONSON, Tamlyn. Towards Tolerance, Law, and Dignity: Addresssing Violence against Foreign Nationals in South Africa. Johanneburg: IOM and the Department for International Development (DFID) University of the Witwatersrand, 2009.

MiWORC. Migrancy and labour in the hospitality sector in South Africa. African Centre for Migration and Society (ACMS). 2014.

MOHAMED, Seeraj. Industrial policy for economic development proposals. In: EDIGHEJI, Omano (ed.). Rethinking South Africa's Development Path: Reflections on the ANC's Policy Conference Discussion Documents. Johannesburg: Centre for Policy Studies: 2007, p. 81-85.

NAICKER, Camalita. South African student protests herald the re-emergence of people's power. Scroll.in. 2015. Available at: <http://scroll.in/article/764715/ south-african-student-protests-herald-the-re-emergence-of-peoples-power $>$.

NEOCOSMOS, Michael. From 'Foreign Natives' to 'Native Foreigners': Explaining Xenophobia in Post-Apartheid South Africa. Dakar: CODESRIA Monograph Series, 2006.

NEOCOSMOS, Michael. Neocosmos: The Politics of Fear and the Fear of Politics (Essay on the pogroms). Abahlali baseMjondolo. Home of the Abhlali baseMjondolo Shackdwellers' Movement South Africa. 2008. Available at: < http://abahlali.org/ node/3616/>.

NEOCOSMOS, Michael. Transition, human rights and violence: rethinking a liberal political relationship in the African neo-colony. Interface: a journal for and about social movements, v. 3, n. 2, p. 359-99, 2011. 
NEOCOSMOS, Michael. The sickness of xenophobia, and the need for a politics of healing. The Daily Maverick, 2015. Available at: < http://www.dailymaverick. co.za/opinionista/2015-02-02-the-sickness-of-xenophobia-and-the-need-for-apolitics-of-healing/\#.VQURZeGBtc8>.

NEWMAN, Susan; TAKALA-GREENISH, Lotta. African Industrialisation: Is Global Value Chain Development the Answer? Joint South Africa-EU initiative, TIPS and Dialogue Facility Conference: International Conference on Manufacturing-Led Growth for Employment and Equality. Johannesburg, 20-21 May 2014.

NORTHCOTE, Madeleine Ann. Enterprising Outsiders: Livelihood Strategies of Cape Town's forced migrants. Electronic Thesis and Dissertation Repository, Paper 2806, London, Ontario: Western University, 2015.

OECD. OECD Economic Surveys: South Africa. Paris: OECD, 2013.

OXFAM. Is South Africa Operating in a Safe and Just Space? Oxford: OXFAM, 2013. PAYN, Jonathan. 'Xenophobia', service delivery protest and government failure: The case of Thembelihle. anarkismo.net. 2015. Available at: <http://www. anarkismo.net/article/28228>.

POLANYI, Karl. The Great Transformation: The Political and Economic Origins of Our Time. Boston, MA: Beacon Press, 1957 (1944).

RANSLEM, Duncan. 'Temporary' relocation: spaces of contradiction in South African law. International Journal of Law in the Built Environment, v. 7 n. 1, p. 55-71, 2015.

RICHARDS, Howard. Neville Alexander, Unbounded Organisation, and the Future of Socialism. TRANSCEND Media Service. 2012. Available at: <https://www. transcend.org/tms/2012/12/neville-alexander-unbounded-organisation-and-thefuture-of-socialism/>.

RICHMOND, A. H. Global Apartheid: Refugees, Racism, and the New World Order. Toronto, New York, and Oxford: Oxford University Press, 1994.

SAMSON, Melanie. (Sub)imperial South Africa? Reframing the Debate. Review of African Political Economy, v. 36, n. 119, p. 90-103, 2009.

SATGAR, Vishwas. Vishwas Satgar: Reclaiming a Vision of Hope and a Life of Dignity: Neoliberal South Africa and the Narrowing of Democratic Space. keynote address delivired by Vishwas Satgar at a Conference of the democratic left. Constitutionally Speaking. 2011. Available at: <http://constitutionallyspeaking.co.za/vishwassatgar-reclaiming-a-vision-of-hope-and-a-life-of-dignity-neoliberal-south-africaand-the-narrowing-of-democratic-space/> .

SATGAR, Vishwas. Beyond Marikana: The Post-Apartheid South African State. Africa Spectrum, v. 47, n. 2-3, p. 33-62, 2012.

SCHIERUP, Carl-Ulrik. A Toxic Embrace: Migration, Labour, and the Rainbow Nation's Neoliberal Pact. In: IDEM et alii (eds.). Migration, Precarity, and Global Governance: Challenges for Labour. Oxford: Oxford University Press: 2015, p. 197-222.

SCHIERUP, Carl-Ulrik; ALUND, Aleksandra; KINGS, Lisa. Reading the Stockholm riots - a moment for social justice? Race \& Class, v. 55, n. 3, p. 1-21, 2014. 
SCHIERUP, Carl-Ulrik; MUNCK, Ronaldo; LIKIC-BRBORIC, Branka; NEERGAARD, Anders (eds.). Migration, Precarity and Global Governance. Challenges and Opportunities for Labour. Oxford: Oxford University Press, 2015.

SEEKINGS, Jeremy. Poverty and Inequality after Apartheid. The second 'After Apartheid Conference. Yale University, New Haven, 27-28 April 2007.

SEEKINGS, Jeremy; NATTRASS, Nicoli. Class, Race, and Inequality in South Africa. New Haven: Yale University Press, 2005.

SEGATTI, Aurelia. Reforming South African Immigration Policy in the Postapartheid Period (1990-2010). In: SEGATTI, Aurelia; LANDAU, Loren B. (eds.). Contemporary Migration to South Africa: A Regional Development Issue. Washington: The International Bank for Reconstruction and Development / The World Bank, 2011.

SEWELL, Rob. Lenin on the national question. In Defence of Marxism. 2004. Available at: <http://www.marxist.com/lenin-national-question160604.htm>.

SEYMOUR, Richard. We Are All Precarious - On the Concept of the 'Precariat' and its Misuses. New Left Project. 2012. Available at: <http://www.newleftproject. org/index.php/site/article_comments/we_are_all_precarious_on_the_concept_ of_the_precariat_and_its_misuses $>$.

SIVANANDAN, Ambalavaner. Poverty is the new black. Race \& Class, v. 43 n. 1, p. 1-5, 2001.

SLAVNIC, Zoran. Political Economy of Informalization. European Societies, v. 12, n. 1, p. 3-23, 2010.

SLOVO, Joe. The South African Working Class and the National Democratic Revolution. African Socialism Archive. 1988. Available at: < https://www.marxists. org/subject/africa/slovo/1988/national-democratic-revolution.htm>.

STANDING, Guy. The Precariat. The New Dangerous Class. London: Bloomsbury Academic, 2011.

TATI, Gabriel. The immigration Issues in the Post-Apartheid South Africa: Discourses, Policies and Social Repercussions. Géopolitique et populations, n. 3, p. 423-40, 2008.

TERREBLANCHE, Sampie. A History of Inequality in South Africa 1652-2002. Durban: University of KwaZulu-Natal Press, 2003.

THERON, Jan. Sour grapes. Law, Democracy and Development, n. 14, p. 1-21, 2010a.

THERON, Jan. Informalization from above, informalization from below: The options for organization. African Studies Quarterly, v. 11, n. 2-3, p. 87-105, 2010 b.

TRIMIKLINIOTIS, Nicos; GORDON, Steven; ZONDO, Brian. Globalisation and Migrant Labor in a Rainbow Nation: a fortress South Africa? Third World Quarterly, v. 29, n. 7, p. 1323-39, 2008.

TSHABALALA, Xolani. Waiting on the Move: The Social Life of Mobility Governance Across the Beitbridge Border. REMESO. Linköping University, Norrköping, 2015. 
TSIANOS, Vassilis; KARAKAYALI, Serhat. Transnational Migration and the Emergence of the European Border Regime: An Ethnographic Analysis. European Journal of Social Theory, v. 13, n. 3, p. 373-87, 2010.

TUTU, Desmond. No Future without Forgiveness. New York: Doubleday, 1999.

UMSEBENZI. Forward to the anc NGC! And a 2nd, more radical phase of the NDR. Umsebenzi. Voice of the South African Communist Party. 2015. Available at: <http://www.sacp.org.za/pubs/umsebenzi2/2015/oct.pdf>.

UPM. Unemployed People's Movement. 2013.

VIGNESWARAN, Darshan. Free Movement and the Movement's Forgotten Freedoms: South African Representation of Undocumented Migrants. Refugee Studies Centre. 2007. Available at: <http://www.queensu.ca/samp/migrationresources/ vigneswaran.pdf $>$.

WAITE, Louise. A Place and Space for a Critical Geography of Precarity? Geography Compass, v. 3, n. 1, p. 412-33, 2008.

WENTZEL, Marie; TLABELA, Kholadi. Historical background to South African migration. In: KOK, Pieter et alii (eds.). Migration in South and Southern Africa. Dynamics and Determinants. Cape Town: HSRC Press, 2006.

WILLÉN, Julia. The curse of the nation state and history as remedy? Xenophobia and migritude in post-apartheid South Africa. Discover Society, n. 17, February 2015.

WOLPE, Harold. Capitalism and cheap labour-power in South Africa: from segregation to Apartheid. Economy and Society, v. 1, n. 4, p. 425-456, 1972.

XULU, Nomkhosi. COSATU and internal migrant workers: Old fault lines, new dilemmas. In: BULUNGU, Sakhela; TSHOAEDI, Malehoko (eds.). COSATU's Contested Legacy: South Arrican Trade Unions in the Second Decade of Democracy. Cape Town: HSRC Press: 2010, p. 212-27.

Recebido para publicação em 14.05.2018

Aceito para publicação em 31.10.2018

Received for publication in May 14 ${ }^{\text {th }}, 2018$

Accepted for publication in October 315t, 2018

ISSN impresso 1980-8585

ISSN eletrônico 2237-9843

http://dx.doi.org/10.1590/1980-85852503880005407 